Florida International University FIU Digital Commons

$3-22-2012$

\title{
Comparative Reproductive Biology of a Rare Endemic Orchid and its Sympatric Congeners in Southwestern China
}

Wuying Lin

Florida International University, wlin006@fiu.edu

DOI: $10.25148 /$ etd.FI12041906

Follow this and additional works at: https://digitalcommons.fiu.edu/etd

\section{Recommended Citation}

Lin, Wuying, "Comparative Reproductive Biology of a Rare Endemic Orchid and its Sympatric Congeners in Southwestern China" (2012). FIU Electronic Theses and Dissertations. 570.

https://digitalcommons.fiu.edu/etd/570 


\section{FLORIDA INTERNATIONAL UNIVERSITY}

Miami, Florida

COMPARATIVE REPRODUCTIVE BIOLOGY OF A RARE ENDEMIC ORCHID

AND ITS SYMPATRIC CONGENERS IN SOUTHWESTERN CHINA

A thesis submitted in partial fulfillment of

the requirements for the degree of

MASTER OF SCIENCE

in

ENVIRONMENTAL STUDIES

by

Wuying Lin 
To: Dean Kenneth G. Furton

College of Arts and Sciences

This thesis, written by Wuying Lin, and entitled Comparative Reproductive Biology of a Rare Endemic Orchid and its Sympatric Congeners in Southwestern China having been approved in respect to style and intellectual content, is referred to you for judgment.

We have read this thesis and recommend that it be approved.

Suzanne Koptur

Joel Heinen

Michael Ross

Hong Liu, Major Professor

Date of Defense: March 8, 2012

The thesis of Wuying Lin is approved.

Dean Kenneth G. Furton

College of Arts and Sciences

Dean Lakshmi N. Reddi

University Graduate School

Florida International University, 2012 
C Copyright 2012 by Wuying Lin

All rights reserved. 


\section{DEDICATION}

I dedicate this thesis to my parents, and my boyfriend Zhao Zhong. Without their support, it would not have been possible to finish this study successfully. Without their love, I would not have had the courage to complete this journey.

I also want to dedicate this thesis to many friends that I love and love me. They always cheer me up when I am down, and share my joys when I am up. 


\section{ACKNOWLEDGMENTS}

I would like to thank my major advisor Dr. Hong Liu for her mentorship and providing me with the opportunity to participate in collaborative ecological research. I also wish to thank the members of my committee, Drs. Joel Heinen, Suzanne Koptur, and Michael Ross for their continuous support and advice. Special thanks to Ting Ying and Xiaokai Ma for their great help with the fieldwork. I also thank all the field assistants from Yachang Orchid Nature Reserve and Guangxi University. Lastly, thanks to all my friends at the Department of Earth and Environment who have always shown their great support during my graduate studies.

This study was supported by grants from the Guangxi Chairman's Foundation (09203-04), the Mohamed bin Zayed species conservation fund (0905324), and Fairchild Tropical Botanic Garden. 


\title{
ABSTRACT OF THE THESIS \\ COMPARATIVE REPRODUCTIVE BIOLOGY OF A RARE ENDEMIC ORCHID AND ITS SYMPATRIC CONGENERS IN SOUTHWESTERN CHINA
}

\author{
by \\ Wuying Lin \\ Florida International University, 2012 \\ Miami, Florida \\ Professor Hong Liu, Major Professor
}

Comparative studies on endangered species and their more common congeners can shed light on the mechanism of species rarity, and enable conservationists to formulate effective management strategies. I compared the breeding and pollination systems of the endangered Geodorum eulophioides and its two more common sympatric congeners in subtropical China. Geodorum eulophioides and G. recurvum were self-compatible, both depending on Ceratina cognata for fruit production, while G. densiflorum can autonomously self. Although the floral visitation frequency of G. eulophioides was the highest among the three, its natural fruit set was similar to that of G. recurvum, but both lower than that of $G$. densiflorum. These results partially explain the difference in species abundance. Coupled with severe habitat loss and degradation, the extremely low pollinator visitation and natural fruit set of $G$. eulophioides calls for rapid establishment of ex-situ collection, in conjunction with improving in-situ habitat. Natural hybridization tendencies were also studied among species. 


\section{TABLE OF CONTENTS}

CHAPTER

PAGE

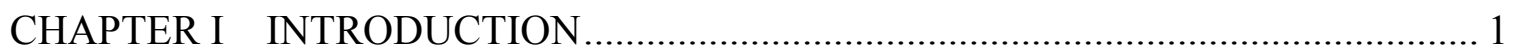

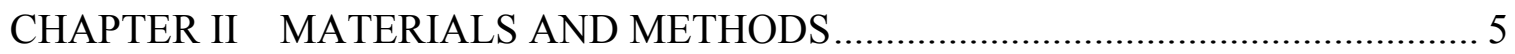

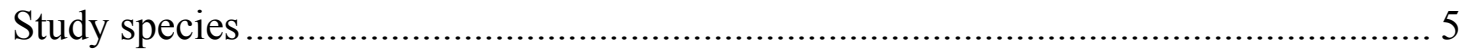

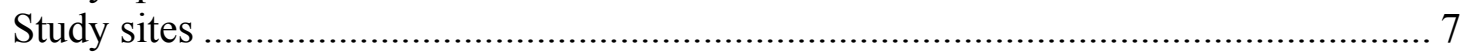

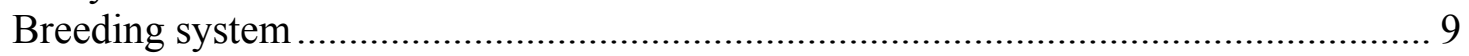

Percentage of Seeds with Embryos ....................................................................... 10

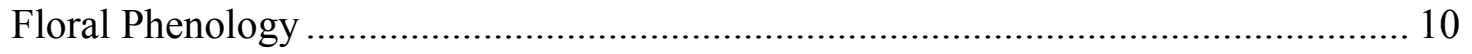

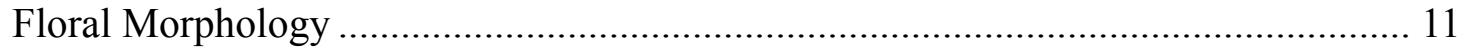

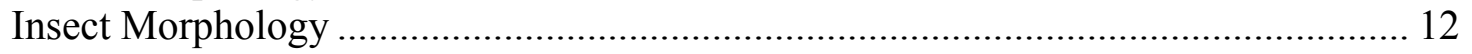

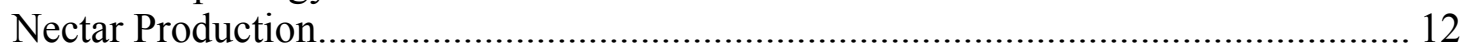

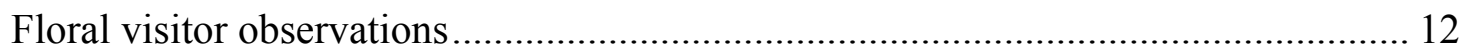

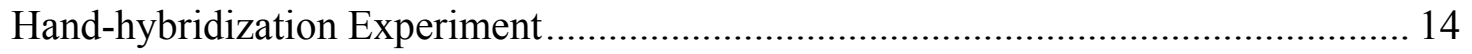

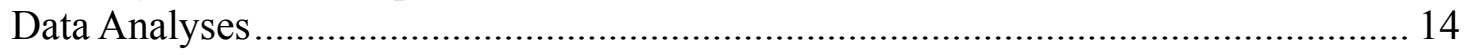

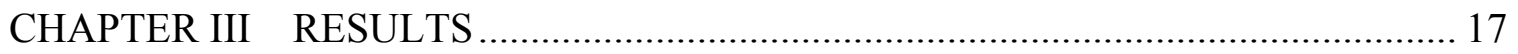

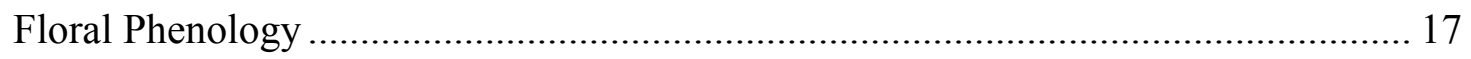

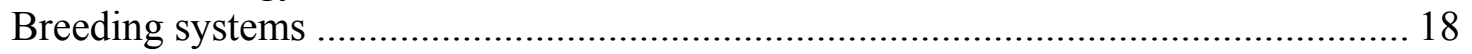

Natural fruit set comparison across species …………............................................. 21

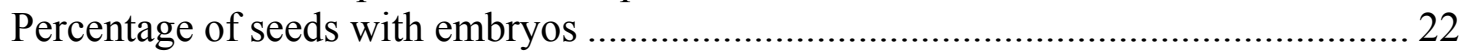

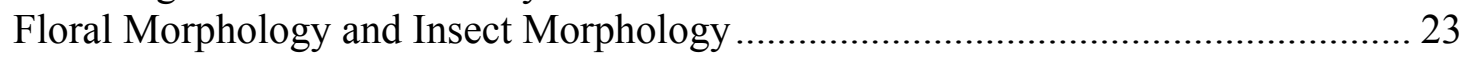

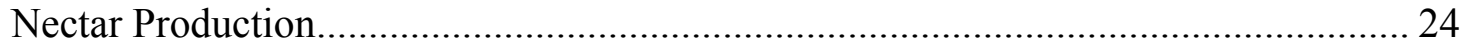

Observations of floral visitors ............................................................................. 24

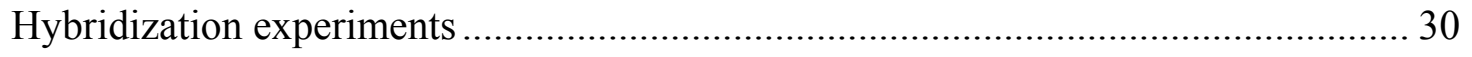

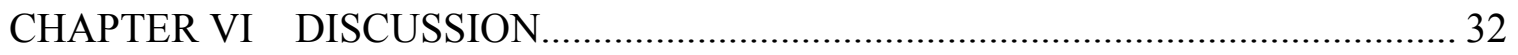

Does the breeding system of $\mathrm{G}$. eulophioides differ from those of its more common

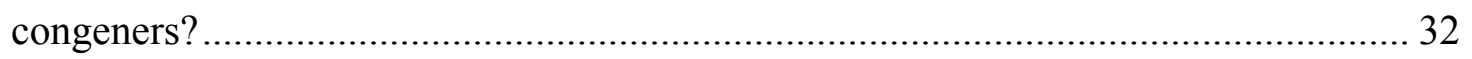

Does G. eulophioides have fewer pollinators and/or less frequent pollinator visits? 33

Does G. eulophioides set fewer fruits per flower naturally? ...................................... 33

Do fruits of G. eulophioides have a smaller percentage of viable seeds than fruits of

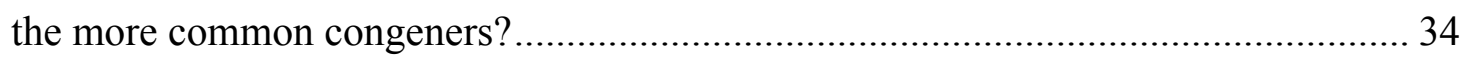

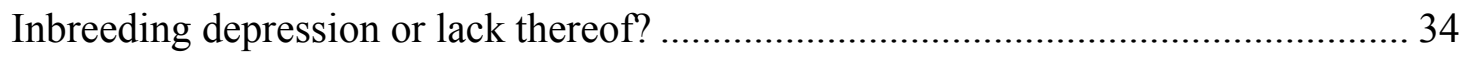

Can G. eulophioides hybrid with G. recurvum and G. densiflorum naturally? ........... 35

What are the potential consequences of natural hybridization? .................................. 37

Conservation implications for the rare G. eulophioides........................................... 38

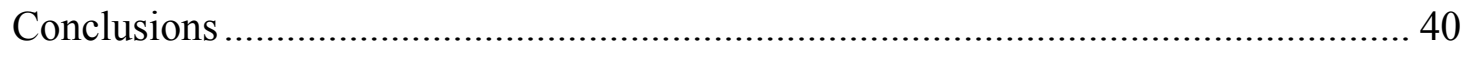

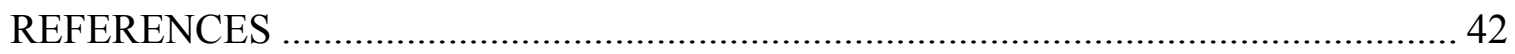


APPENDICES 


\section{LIST OF FIGURES}

FIGURE

PAGE

1. Three sympatric Geodorum species around Yachang Orchid Nature Reserve: A. G. eulophioides; B. G. recurvum; C. G. densiflorum.................................................. 6

2. Location of Yachang National Orchid Nature Reserve ....................................... 8

3. Phenology of three Geodorum species ....................................................... 18

4. Comparison of fruit set under different treatments of three sympatric Geodorum

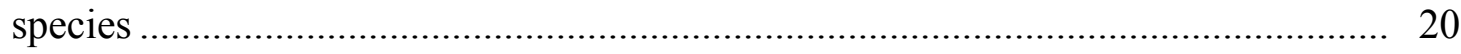

5. Comparison of natural fruit sets by Geodorum species........................................ 22

6. Pie charts of percentage of time (seconds) occupied by different floral visitors for the three sympatric Geodorum species ............................................................. 27

7. Comparison of visitation rates by Ceratina cognata Smith. (A) and by all visitors pooled (B) among three Geodorum species. 


\section{CHAPTER I INTRODUCTION}

Rarity is one of the species abundance patterns in the natural world (Bevill and Louda, 1999), and is becoming increasing common. Probing the reasons of species rarity has interested biologists and conservationists for a long time, and has become one of the most important research areas for conservation biology (Rabinowitz, 1981; Fiedler and Ahouse, 1992; Gaston and Kunin, 1997; Bevill and Louda, 1999; Burne et al., 2003). Studies of species rarity are also very important for the development of related ecological theory (Bevill and Louda, 1999) as the mechanisms underlying species rarity can add to our understanding of species' adaptation and evolutionary processes.

Many causes of species rarity have been proposed and tested. These include natural causes, including the geological and evolutionary history of the taxon, life history traits, and ecological interactions, as well as human-induced factors such as habitat destruction and alteration, and overexploitation (Rabinowitz, 1981; Fiedler and Ahouse, 1992; Burne et al., 2003). In the plant kingdom, intrinsic traits and factors that are related to breeding systems, pollination patterns, dispersal, competitive ability, and resource use capability can critically influence population abundance (Burne et al., 2003; Gaston and Kunin, 1997). Generally speaking, species having more specific requirements from the surrounding environments will be more vulnerable to becoming rare or endangered (Darwin, 1877; Van der Pijl and Dodson, 1966; Dressler, 1981; Tremblay et al., 2005; Bernhardt et al., 2010) because being "picky" makes them more vulnerable to natural or human-induced environmental changes. Examples of these specific requirements include complete dependency on one or a few species for pollination, particular seed dispersal 
requirements, or specific nutrient needs. Many species in the Orchidaceae are among the most vulnerable plants because of their highly specific environmental requirements for pollination, and seed germination (Dixon et al., 2003).

The orchid family is one of the world's most diverse angiosperm families, with an estimated 25,000 species (Dressler, 1993). Orchids are seen as the "pandas" of the plant kingdom because of their rareness and charisma (Dixon et al., 2003; Swarts et al., 2009). Many orchids are well known for their specialized pollination systems, in which their flowers can only be pollinated by one, or relatively few, animal species of the same family, genus, and sometimes even the same sex (Tremblay, 1992; Dressler, 1993; Johnson et al., 1998).

The combination of highly specialized floral structures and commonly reward-free floral characters are responsible for the high degree of pollinator-limitation and low reproductive success in many orchid species (Darwin, 1877; Van der Pijl and Dodson, 1966; Dressler, 1981; Smithson, 2002; Tremblay et al., 2005). Low reproductive success has been proposed as a cause for rarity in some orchid species. Furthermore, human induced threats, such as habitat destruction and alteration and/or over- collection have caused orchids to become rarer, even resulting in extinction (Dressler, 1993; Dixon et al., 2003).

Comparative study that contrasts traits between rare and common species is a very useful approach to understanding species rarity (Kunin and Gaston, 1993; Baskin et al., 1997; Bevill and Louda, 1999). Pairwise comparisons between carefully chosen rare vs. common relatives can suggest which factors contribute to the rarity of a taxon of interest (Baskin et al., 1997; Bevill and Louda, 1999). Because closely related species share the 
same ancestors and retain similar historical evolutionary routes, confounding factors are minimized when inferences are made regarding the causes of differences in population abundances. However, such studies underlying both empirical knowledge and management practice of rare plant species are also rare, making it difficult to uncover the mystery of species rarity (Bevill and Louda, 1999).

Moreover, natural hybridization is also generally suspected as a threat for rare species and considered harmful for biodiversity conservation (Anderson 1948; Stebbins 1959; Arnold \& Bennett 1993; Levin et al., 1996). Interspecific gene flow is commonly seen as a threat in plant conservation, particularly when rare species are in contact and hybridize with their more common and widespread relatives (Schierenbeck, 2000; Ferdy and Austerlitz, 2002). Hybridization may cause the loss of rare species as a result of outbreeding depression and genetic assimilation (Allendorf et al., 2001; Arnold, 1997). In general, more advanced families show a higher frequency of interspecific hybridization (Ellstrand et al., 1996). The orchid family is also such a typical example of this tendency (Pellegrino et al., 2009).

Geodorum eulophioides Schltr. is a rare, showy, ground orchid with a very narrow global distribution. It occurs in two adjunct locations: a short stretch of the Hongshui River banks in Southwest China (Liu, 2010), and in central Myanmar (Tanaka et al., 2011). Two other sympatric Geodorum species, G. recurvum (Roxb.) Alston and $G$. densiflrorum (Lam.) Schltr., are also present at the Hongshui River site. Local populations of G. recurvum are also few and small in the region. However, this species has a wider global geographic distribution, with occurrences in other parts of tropical China and a few countries in Southeast Asia (i.e., Cambodia, Myanmar, Thailand, and 
Vietnam), as well as in India (Chen et al., 2009). In contrast, G. densiflorum is much more abundant locally and has a wider global distribution than either of other two species, occurring in tropical and subtropical China and Asia, as well as Northern Australia (Chen et al., 2009). Additionally, in the Hongshui River region, G. eulophioides and G.

recurvum have narrower vertical ranges ( $<500 \mathrm{~m}$ above sea level) than does $G$. densiflorum ( $<1000 \mathrm{~m}$ above sea level; Lin et al., unpublished data; Feng et al., in press).

To help establish feasible in-situ restoration and ex-situ conservation plans for the narrowly endemic and endangered G. eulophioides, I compared the reproductive ecology of this species with its two wider ranging, sympatric congeners, G. recurvum and $G$. densiflorum. I hypothesized that differences in breeding systems, pollination patterns, natural fruit set and percentage of viable seeds may have contributed to the rarity of $G$. eulophioides. I also hypothesized that the possibility of natural hybridization between $G$. eulophioides and its two sympatric congeners might be a threat to the natural population of G. eulophioides. I addressed the following specific questions: (1) Does the breeding system of G. eulophioides differ from that of its more common congeners? If so, in what ways? (2) Does G. eulophioides have fewer pollinators and/or less frequent pollinator visits? (3) Does G. eulophioides set fewer fruits per flower naturally? (4) Do fruits of G. eulophioides have a smaller percentage of viable seeds than fruits of its more common congeners? And (5) Can G. eulophioides hybridize with G. recurvum and G. densiflorum naturally? 


\section{CHAPTER II MATERIALS AND METHODS}

\section{Study species}

Our focal species - Geodorum eulophioides Schltr. (Fig. 1A), is an endangered and narrowly endemic orchid species, occurring in a short stretch of the valley along the Hongshui River near Yachang National Orchid Nature Reserve (hereafter refer to as Yachang Reserve) of Guangxi Zhuang Autonomous Region in southwestern China (Liu, 2010), and in central Myanmar (Tanaka et al., 2011). No additional specimens of this rare orchid were found in China since its first description in 1921, until 2005, when a population of $G$. eulophioides with several dozen reproductive plants was discovered on a small hill in Bajiang village, on the border with Luodian, adjacent to the Yachang Reserve (Liu, 2010). At the same site, there were two other Geodorum species growing, G. recurvum and G. densiflorum (Fig. 1B, and Fig. 1C). All three species flowered in the summer. Flowers of G. eulophioides have distinct red petal tips while those of $G$.

recurvum are completely white (Chen et al. 2009; personal observations). Flowers of $G$. densiflorum are either pink or white, with purple stripes on the labellum, and flowers packed more densely in the inflorescence than either of its congeners. (Chen et al., 2009; Lin et al., personal observations). 
Fig. 1 Three sympatric Geodorum species around Yachang Orchid Nature Reserve: A. G. eulophioides; B. G. recurvum; C. G. densiflorum.
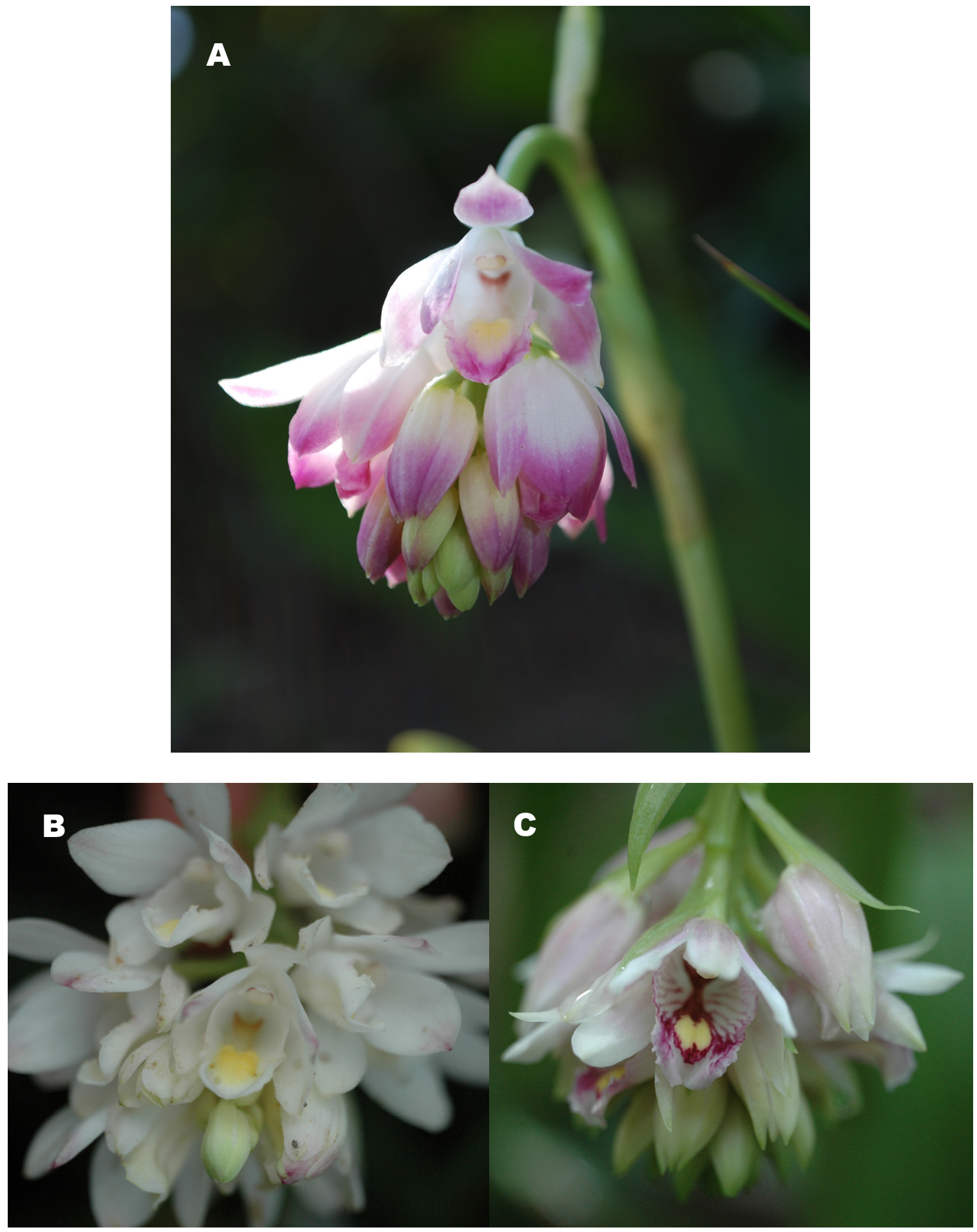


\section{Study sites}

The study was carried out near the Yachang Reserve in Guangxi, southwestern China (Fig. 2). The Yachang Reserve is located between $24^{\circ} 44^{\prime} 16^{\prime \prime}$ to $24^{\circ} 53^{\prime} 58^{\prime \prime} \mathrm{N}$, and $106^{\circ} 11^{\prime} 31^{\prime \prime}$ to $106^{\circ} 27^{\prime} 04^{\prime \prime} \mathrm{E}$, in the transition zone between the subtropical and temperate regions influenced mostly by a subtropical monsoon climate (Corlett, 2009). The Reserve exemplifies southwestern China's reputation as a world orchid hotspot (Dixon et al., 2003), harboring more than 140 species of orchids in an area of 220 square kilometers. Seasonal variation in both rainfall and temperature are prominent in the region (Corlett and LaFrankie, 1998; Huang et al. 2008), with nearly $70 \%$ of the rainfall occurring in the hot summer months (Huang et al. 2008).

Our primary study site was a small hill near Bajiang village, where all three Geodorum species were found. The site is located at $\sim 450 \mathrm{~m}$ in elevation on the south side of the Hongshui River adjacent to the Yachang Reserve (N 24 $50^{\prime}$, E $106^{\circ} 14^{\prime}$ ). The local climate in Bajiang is hot and dry, with an average annual temperature of $20.4^{\circ} \mathrm{C}$ and annual precipitation of $940.8 \mathrm{~mm}$ (mostly occur in summer). Even before farming started in 2008, vegetation at Bajiang had been highly disturbed over the past three decades because of aggressive timber harvesting of the main canopy trees, the Yunnan thin-leaved pine (Pinus yunnanensis var. tenuifolia), and grazing by goats and cows. At the time of the study, canopy-size Yunnan thin-leaved pines were rare, and the vegetation was dominated by newly planted, introduced Eucalypt trees (intended as a pulp source) and the invasive shrub Chromolaena odoratum (L.) R. King et H. Rob. A few native species, e.g., Dendrolobium triangulare (Retz.) Schindl., Callicarpa macrophylla Vahl, and Cryptolepis buchananii Roem. et Schult occurred as remnants throughout the site. 
I carried out the study of breeding systems and hand-hybridization experiments of all three Geodorum species at the Bajiang site in 2009. In 2010, the breeding system study was repeated for G. eulophioides in Bajiang, but I was unable to find an adequate number of either G. densiflorum or G. recurvum as a result of the farming disturbance. As a consequence, in that year I studied the breeding system of $G$. densiflorum at two other study sites, Ergou and Jinkuangshibi, inside the Yachang Reserve. Both sites were less than $10 \mathrm{~km}$ away from Bajiang. No additional plants of G. recurvum were studied in 2010.

Fig. 2 Location of Yachang National Orchid Nature Reserve.

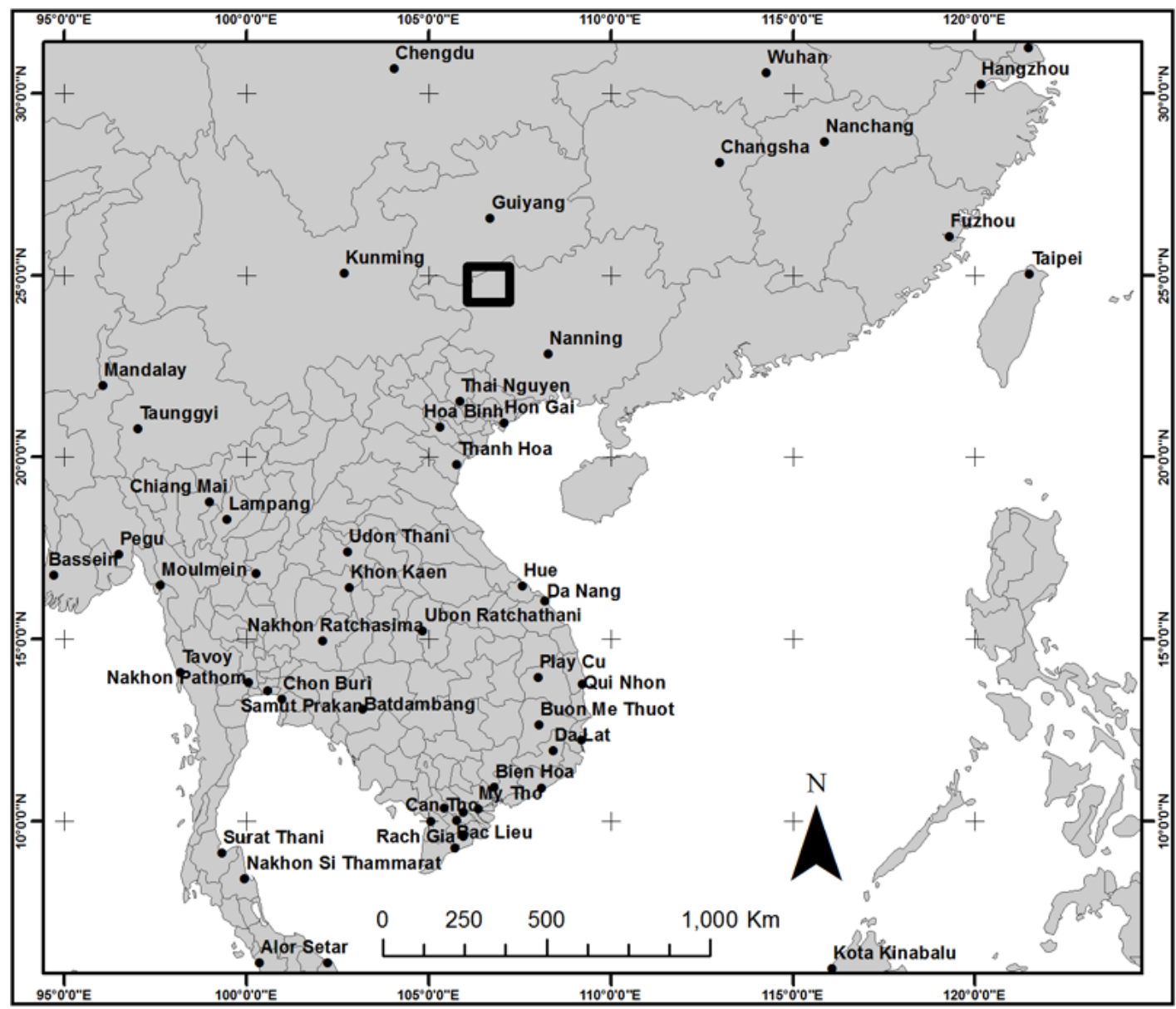




\section{Breeding system}

Controlled hand-pollination experiments were conducted to determine the breeding systems of three Geodorum species. The following four treatments were performed: (a) pollinator exclusion (bagged), (b) artificial self-pollination (bagged prior to flower opening, and after hand-pollination), (c) artificial outcross-pollination (bagged as the previous treatment) and (d) control (unbagged unmanipulated treatment). Because $G$. densiflorum can self-pollinate automatically (see results), I added an additional treatment, in which I removed the pollinia prior to bagging the flowers to test for the possibility of apomixis. The pollinator exclusion treatment was to test the dependency of fruit set on animal pollinators; for this exclusion, inflorescences with only flower buds, or flowers with pollinia neither removed nor deposited, were bagged.

The self-pollination treatment, performed to test for self-compatibility, was accomplished by removing a pollinium from a virgin flower using a toothpick and immediately depositing it onto the stigma of the same flower, or a different flower on the same plant. The cross-pollination treatment was accomplished in a similar fashion except that the pollinium was deposited onto a stigma of a flower of a different plant that was at least $5 \mathrm{~m}$ away. For all three species, fruit set of the unmanipulated controls were calculated from tagged plants that were monitored for a concurrent demographic study at the Bajiang site. The proportions of fruit set among orchid species and among the four treatments within particular species were compared.

In 2009, treatment replicates were individual plants. To increase statistical power and control for variation among individual plants, I carried out the pollination treatments again in the flowering season of 2010 , but used individual flowers as the replication units. 
Specifically, I performed the bagging and the two hand-pollination treatments on the same plants in an alternating fashion on a given inflorescence. Each inflorescence typically accommodated 2-3 sets of treatments. In this way, I controlled for variation associated with differences among individual plants.

\section{Percentage of Seeds with Embryos}

Seed viability is an important indicator of reproductive success. Because of the rarity and conservation status of G. eulophioides, I used a non-destructive method, the presence of embryos, as an indication of viability. I quantified the proportion of seeds with embryos for each treatment and species.

I sampled 0-8 fruits for each treatment and species, depending on their availability. Following conservation guidelines, I harvested less than 10\% of natural fruits (Menges et al., 2004). I sampled 2000-3000 seeds from each fruit by spreading them in a petri dish for microscope examination. I sub-sampled 8 to 10 fields of view with four times magnification for each fruit. I counted the number of seeds with an embryo in each field of view, and divided the value by total number of seeds in that field. The values of all sub-samples of the same fruit were averaged for statistical comparisons among treatments and species.

\section{Floral Phenology}

Floral phenology is one of the basic factors dictating whether natural hybridizations among the sympatric congeners are possible. In 2009 and 2010, I monitored and recorded flowering durations at three levels: individual flower, plant and population. A flower was 
recorded as open when its dorsal sepals were separated from the expanded labellum. The functional floral life span was regarded to be over when the labellum withered, collapsed, and the flower closed. The flowering period of an individual plant/population was defined from the opening of the first flower(s) of the plant/population to the closing of the last flower(s); the flowering peak of a population of a given species was defined as the period with the greatest number of flowering individuals. In 2009, I surveyed the flowering status every 2-3 days, and in 2010 every 2-7 days, less frequently because of the knowledge gained in 2009.

\section{Floral Morphology}

Eighteen fully opened G. eulophioides flowers were chosen at random in the population and measured with a vernier caliper (with accuracy of $0.01 \mathrm{~mm}$ ) in 2009 and 2010. In the same way, 11 G. recurvum flowers and 12 G. densiflorum flowers were also sampled and measured. The dimensions of the entrance or passage of an orchid flower, consisting of the terminus of the column (top), labellum med-lobe (bottom), and lateral margins of the labellum (sides), is regarded as a key floral trait that restricts the ability of prospective pollinators to enter and exit. Three measurements of the passage were made: (1) height, defined as the distance between the rostellum and surface of the mid-lobe of the labellum; (2) width, defined as the distance between the two lateral lobes of the labellum at the entrance of the passage; and (3) depth, defined as the full length of the floral passage (floral tube). 


\section{Insect Morphology}

Two specimens of the pollinator Ceratina cognata Smith., and 3 of the frequent visitor Andrenidae sp. were caught during non-watch periods for identification and deposited in the Herbarium (PE), Institute of Botany, Chinese Academy of Sciences as voucher specimens from 2009 and 2011 (Lin et al., unpublished data). For each bee specimen, I measured the head length, abdomen length, thorax length, height, and width (between the wing sockets), the key traits to determine which might be potential pollinator(s), to the nearest $0.01 \mathrm{~mm}$, using a vernier caliper. The insects' visitation behaviors were also observed in 2009 and 2010.

\section{Nectar Production}

Before pollinator observation, I used over-the-counter medical test papers (JWFU brand, China) to test for the presence and concentration of sucrose in nectar in Geodorum flowers. To do this, I cut the test paper into fine strips and inserted them (one per flower) into spurs of the three different Geodorum species' flowers. I carried out this test at 08:30h on four G. eulopioides, four G. densiflorum and three G. recurvum flowers in June 2009.

\section{Floral visitor observations}

To determine the relative visitation frequency of various visitors, I carried out timed floral observations at patches of G. eulophioides, G. recurvum and G. densiflorum flowers from the beginning of June to early July in 2009 at Bajiang, and again from early June to late July in 2010 for G. eulophioides and G. recurvum at Bajiang, and for G. 
densiflorum at Ergou and Jinkuangshibi. Since preliminary observations suggested that visitation frequencies varied with time of day, and floral visitors were not active before 09:00h or after 16:00h at the sites, I carried out the watches from 09:00 to 16:00h. Except for a few cloudy days, I generally carried out these observations on sunny days; rainy days were excluded. Each patch was observed for 20-30 min before I moved to a different patch.

Before each observation period started, the total number of flowers in the patch was counted. Observations in each patch consisted of 1-7 individuals, depending on the number of plants that were available to observe. The number of flowers in the observed patches ranged from 2 to 46 flowers. Since the number of flowers may influence pollinator visitation (Groom, 1998), I quantified the visitation frequency of each visitor type on a per flower basis.

I also recorded the behavior of visitors and classified visits into two categories: "inside" and "outside" visits. A visit was considered "outside" unless the insect entered the pollination channel (from labellum to spur of a flower). Only an "inside" visit has the potential to carry out pollination (i.e., remove and/or deposit pollinaria). The presence of a visitor in the patches was not counted unless the visitor touched the flowers. The percentage of time during the observation period that the flower was occupied by visitors was used as the measure of visit duration.

Floral visitors were usually identified to species or genus; some rare visitors were only identified to family, or placed in categories. Representatives of the floral visitors were caught during non-watch periods for identification, and as voucher specimens, which were deposited in the Herbarium (PE), Institute of Botany, Chinese Academy of 
Sciences. They were identified by Dr. Huanli Xu, an entomologist of the China Agricultural University. For each bee specimen, I measured the head length, abdomen length, thorax length, height, and width (between the wing sockets), to the nearest 0.01 mm, using a vernier caliper.

\section{Hand-hybridization Experiment}

To determine the natural hybridization possibility between $G$. eulophioides and its two sympatric congeners, I carried out reciprocal inter-specific hand pollinations between G. eulophioides and G. recurvum, and G. eulophioides and G. densiflorum. Few inter-specific treatment replicates were performed between $G$. eulophioides and $G$. densiflorum in 2009 because of the limited availability of $G$. eulophioides flowers at the time when $G$. densiflorum flowered (see results below). No attempts were made to potentially hybridize G. eulophioides and $G$, densiflorum was performed in 2010 because there was essentially no overlap in their flowering periods that year. Proportions of fruit set from the interspecific treatments were compared with other hand pollination treatments (see "breeding system") within each pollen recipient species, especially with intraspecific crossed treatments.

\section{Data Analyses}

Breeding system and hybridization experiment

Because preliminary analysis indicated that the fruit set patterns of 2009 and 2010 were consistent within species and treatments, I combined data for these two years to increase the sample size for the final analyses. Since the fruit set data violated 
assumptions of the parametric tests, I used the nonparametric Kruskal-Wallis Test to determine differences in fruit set among treatments, followed by Mann-Whitney $U$ tests for pairwise comparisons with Bonferroni adjustments (Field, 2005). I carried out these tests on each species separately to understand the breeding system of each orchid species. The same statistical tests were also used to compare natural fruit set among species, and the comparison between interspecific treatment and other hand-pollination treatments.

\section{Percentage of seeds with embryos}

An Independent $t$-test was used to compare the percentage of viable seeds between fruits that set naturally on G. eulophioides and G. densiflorum in 2009. I also compared the percentage of viable seeds between self and outcross treatments for G. eulophioides in 2010, and between self and control treatments for G. densiflorum in 2009. I failed to obtain more than one outcross fruit from $G$. densiflorum, and therefore was unable to perform the comparison among treatments on this species. Geodorum recurvum was not included in the seed viability comparison analysis because I could not obtain more than one fruit for each treatment.

Nonparametric Mann-Whitney $U$ test was used to compare the percentage of seeds with embryos among treatments for G. eulophioides in 2010.

\section{Floral visitor observations}

To describe visitation frequencies by different visitors, I calculated the visitation rate (number of visits/ (number of flowers watched * amount of watch time in minutes)) (Dafni, 1992). To express and compare the percentage of observation time occupied by 
floral visitors, I drew two sets of pie charts: one with all observation periods, and another with only periods occupied by at least one floral visitor. The latter set was necessary because the overall percentage of time occupied by all visitors was very low (see results). One-way ANOVA (Analysis of Variance), followed by the Dunnett T3 post-hoc test, was performed to test the difference in visitation rate by confirmed or suspected pollinators among the three orchid species. Visitation rates of all visitors pooled were also compared among orchid species. 


\section{CHAPTER III RESULTS}

\section{Floral Phenology}

Observations during the flowering season from 2009 to 2011 indicated that the $G$. eulophioides population at the Bajiang site usually started to flower from late May or early June and lasted until late June or early July. Its flowering period was largely overlapped with that of G. recurvum (Fig. 3), with G. eulophioides starting to flower 5-7 days earlier. Flowering of both species ended at the same time in 2009 and 2010. In contrast, G. densiflorum started to flower in late June, almost a month after the other two congeners, and finished flowering in mid- or late July. As a consequence, $G$. densiflorum's flowering period barely overlapped those of G. eulophioides and $G$. recurvum or not at all (Fig. 3). 
Fig.3 Phenology of Geodorum spp. in 2009 and 2010. G. eulophioides and G. recurvum flowered during the same period, but their flowering period overlapped little with that of G. densiflorum.
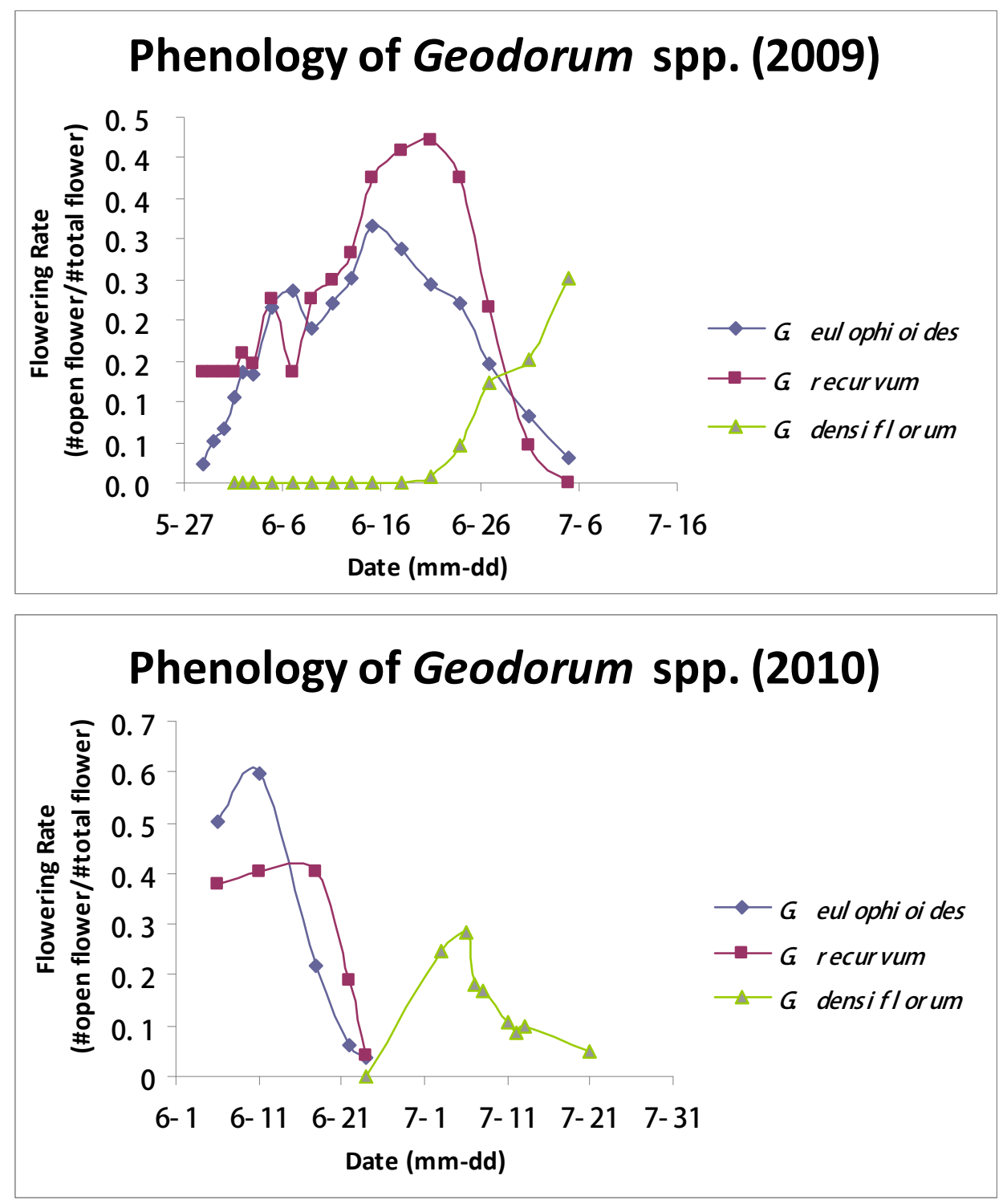

\section{Breeding systems}

\section{Geodorum eulophioides}

Fruit set resulting from all pollination treatments and the unmanipulated controls of this orchid were significantly different $\left(\chi^{2}=49.8, \mathrm{df}=3, P<0.001\right)$. Fruit set of flowers 
with artificially deposited pollinia, regardless of their sources (i.e. self or outcross), were higher than the bagged and control treatments, but were not different from one another (Fig. 4A). In addition, the bagged and control treatments were not different significantly from each other. Note that none of the flowers which were subjected to pollinator exclusion treatments (bagged) set fruit, demonstrating the species' dependency on pollinators for fruit set. The lack of fruit set in the open controls indicates low natural visitation rates.

\section{Geodorum recuvum}

Results of the breeding system analyses of this species (Fig. 4B) were similar to those of G. eulophioide $\left(\chi^{2}=31.8, \mathrm{df}=3, P<0.001\right)$. Outcomes of the pairwise comparisons were also identical to those of G. eulophioides. Similar to G. eulophioides, none of the flowers which were subjected to the bagged treatment set fruits.

\section{Geodorum densiflorum}

There were overall differences among the pollination treatments of this species $\left(\chi^{2}=\right.$ 21.4, $\mathrm{df}=4, P<0.001)$. One major difference between this species and the other two orchids was that some flowers in the bagged treatment set fruit (Fig. 4C). However, flowers subject to pollinia removal and subsequent bagging treatment did not set any fruit, excluding the possibility of apomixis. Pairwise comparisons indicated that self and outcross treatments had significantly higher fruit set than did the pollinia removal treatment, but none of these treatments were significantly different from the bagged or control treatments (Fig. 4C). 
Fig. 4 Comparison of fruit set under different treatments of the three sympatric orchid species: Geodorum eulophioides (A), G. recurvum (B), and G. densiflorum (C). The boxplots showed the five statistics (minimum, first quartile, median, third quartile, and maximum). $\mathrm{N}=$ the number of plants were treated (number of flowers treated).

Treatments share a same letter were not statistically different from one another, while those have different letter were.

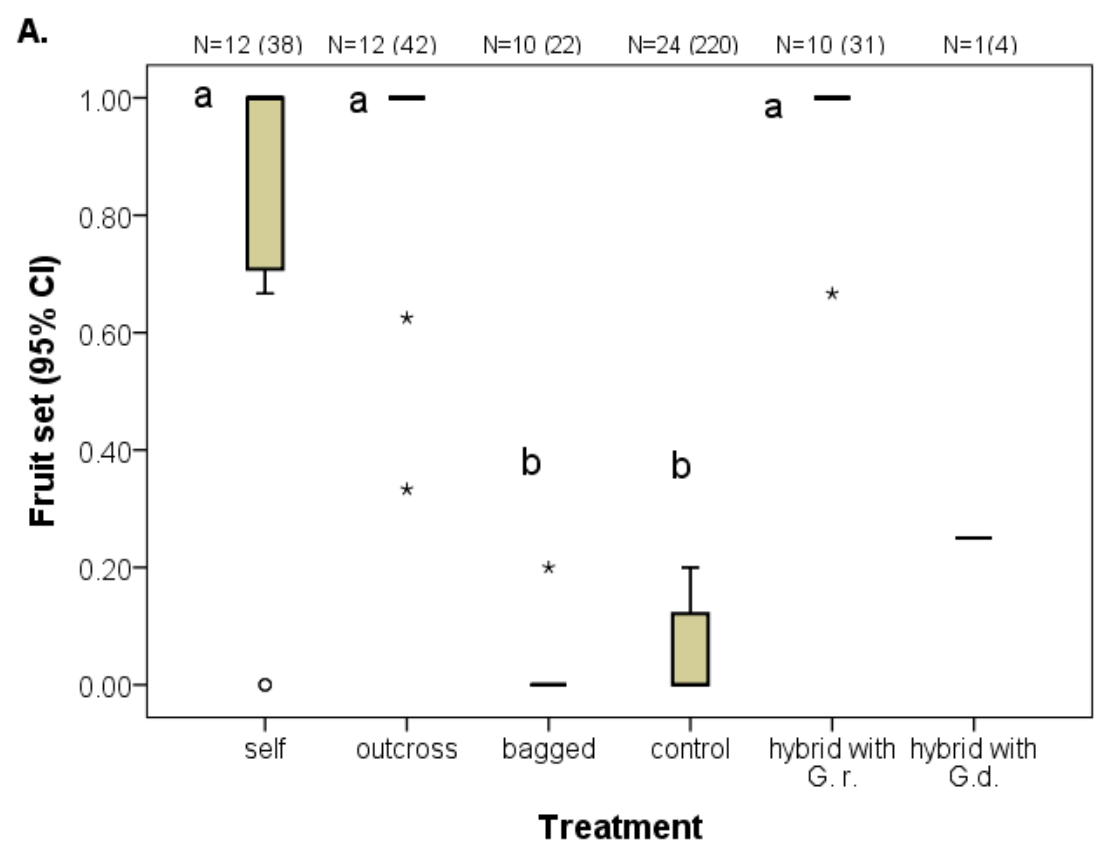



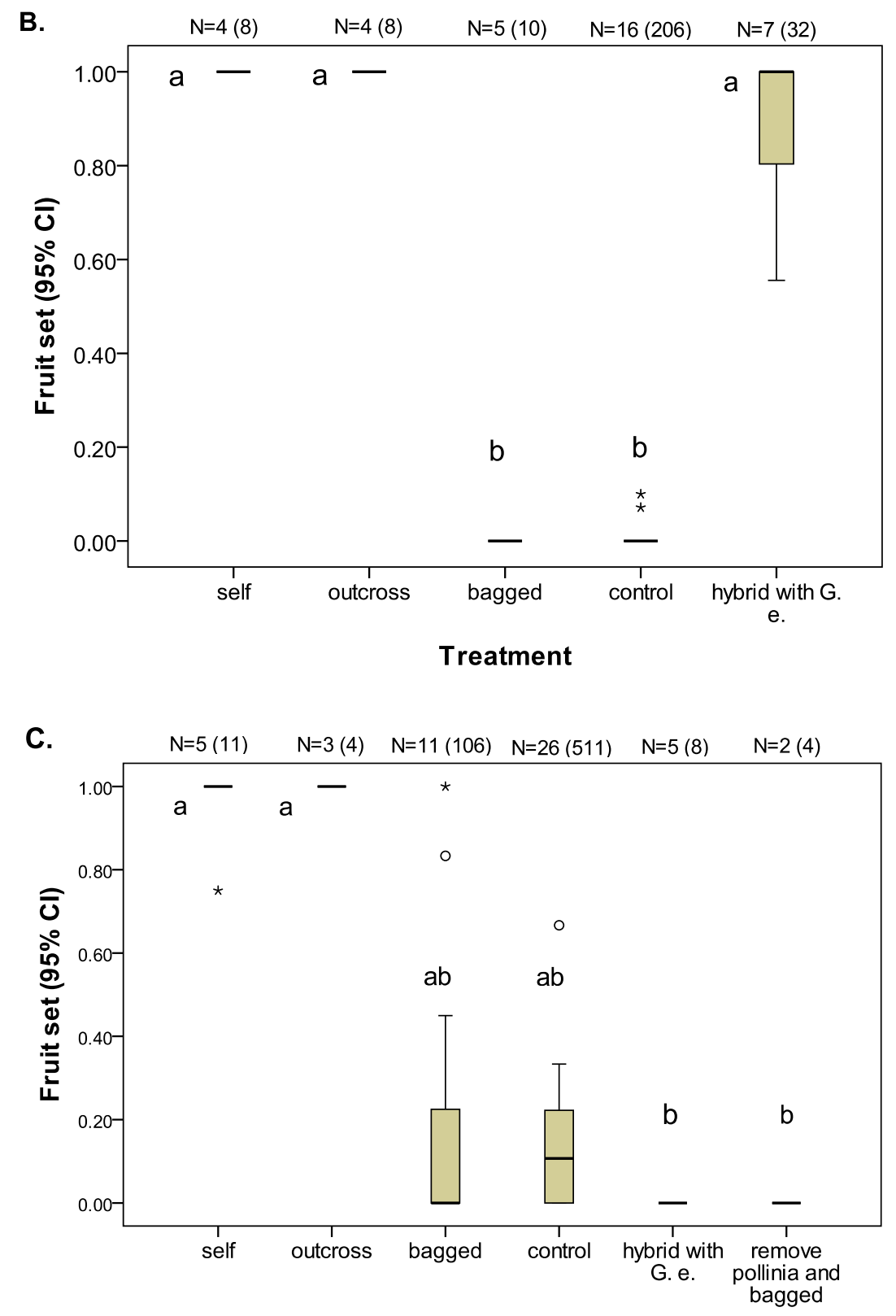

Treatment

\section{Natural fruit set comparison across species}

Natural fruit set rates were significantly different among the three Geodorum species $\left(\chi^{2}=13.5, \mathrm{df}=2, P=0.001 ;\right.$ Fig. 5). G. densiflorum had the highest rate of fruit set, with a median of 0.1067 and range of $0-0.67(\mathrm{~N}=26)$, followed by G. eulophioides with a 
median of 0 and range of $0-0.20(\mathrm{~N}=24)$, and $G$. recurvum with a median of 0 and range of 0-0.10 $(\mathrm{N}=16)$. Natural fruit set of G. eulophioides and G. recurvum were significantly different from that of G. densiflorum, but not different statistically from each other.

Fig. 5 Comparison of natural fruit sets in Geodorum species. The boxplots showed the five statistics (minimum, first quartile, median, third quartile, and maximum). $\mathrm{N}=$ the number of plants were treated. Treatments sharing the same letter were not statistically different from one another, while those with different letters were.

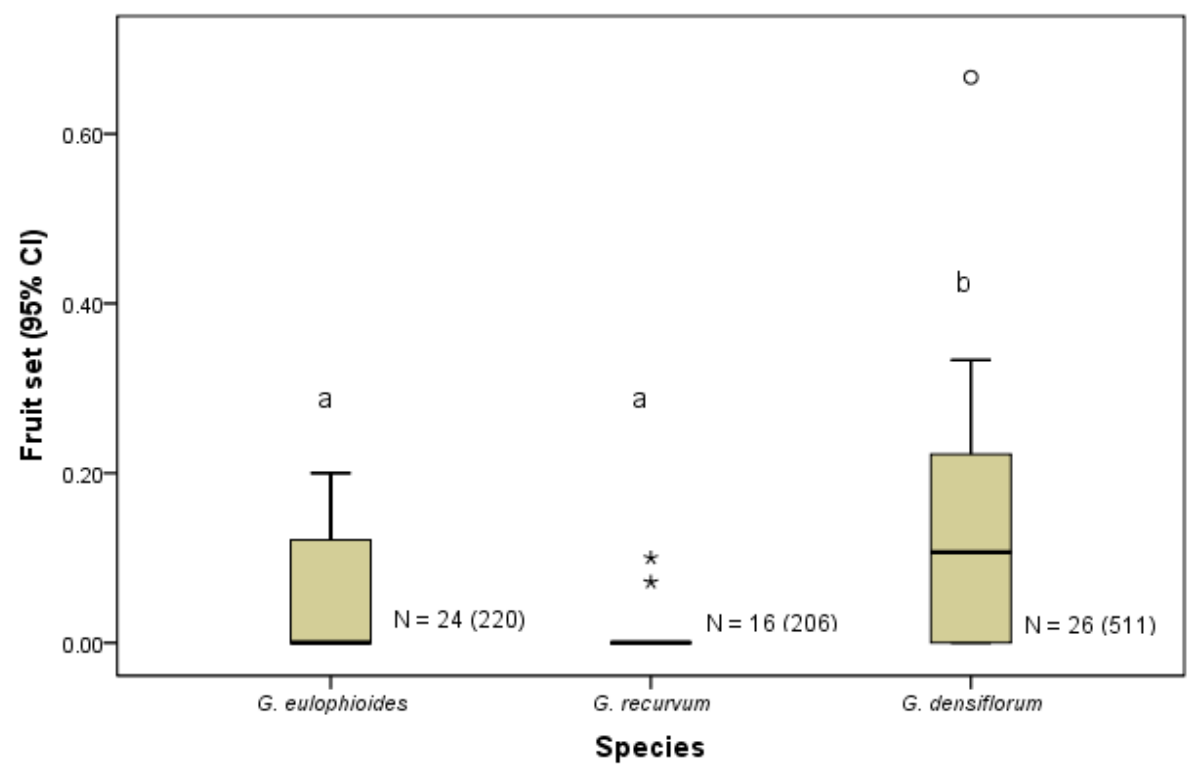

\section{Percentage of seeds with embryos}

The proportion of viable seeds in naturally occuring fruit was $0.572 \pm 0.289$ (mean \pm S.D., $\mathrm{N}=6)$ for $G$. eulophioides, and $0.265 \pm 0.268$ for $G$. densiflorum $(\mathrm{N}=8)$. The difference between the two species was not significant $(t=2.050, \mathrm{df}=12, P=0.063)$. 
In G. eulophioides, the difference in seed viability between self $(0.947 \pm 0.034, \mathrm{~N}=$ 3) and outcross fruits $(0.977 \pm 0.010, \mathrm{~N}=4)$ was not significant $(t=-1.714, \mathrm{df}=5, P=$ $0.147)$. The difference in the proportion of viable seeds between self $(0.277 \pm 0.162, \mathrm{~N}=$ 2) and control $(0.265 \pm 0.268, \mathrm{~N}=8)$ treatments in $G$. densiflorum was not significant either $(t=0.059, \mathrm{df}=8, P=0.954)$.

The hybrid seeds of G. eulophioides had only marginally significant lower percentage of seeds with embryos than did seeds produced by cross-pollinations within a species (Mann-Whitney $U$ test, $P=0.057$ ). We were not able to perform statistical tests on other species due to lack of fruits.

\section{Floral Morphology and Insect Morphology}

The morphological parameters of pollinator entrance, i.e., the height, width and depth of floral tubes, were similar among the three Geodorum species (Table 1). The morphology of the orchids' pollinator, Ceratina cognata Smith., matched that of the floral tubes, especially if the bee's movements while on flowers is taken into consideration. Specifically, the heights of thorax were comparable to the heights of the floral tubes, the widths of thorax matched those of the floral entrances, and the total lengths of insects were comparable with the depths of floral entrances (Table 1). In contrast, Andrenidae sp., a major floral visitor for all three orchid species, was smaller than C. cognata and much smaller than the floral entrances (Table 1). 
Table 1 Key morphological characteristics relevant to pollination of the three

Geodorum species and their main floral visitors found in Yachang Orchid Nature Reserve in southwestern China.

\begin{tabular}{lcccc}
\hline \multirow{2}{*}{ Ordchid Species } & \multicolumn{2}{c}{ Mean (Std. Error) of entrance parameters (mm) } & \multirow{2}{*}{ N } \\
\cline { 2 - 5 } & Height & Width & Depth & \\
\hline Geodorum eulophioides & $3.60(0.13)$ & $5.16(0.16)$ & $7.05(0.08)$ & 18 \\
Geodorum recurvum & $4.02(0.08)$ & $4.82(0.27)$ & $7.30(0.13)$ & 11 \\
Geodorum densiflorum & $4.00(0.17)$ & $6.67(0.26)$ & $7.15(0.14)$ & 12 \\
\hline \multicolumn{1}{c}{ Floral Visitors } & Height of Thorax & Width of Thorax & Total Length & N \\
\hline Ceratina cognata Smith. & $1.87(0.04)$ & $2.25(0.06)$ & $7.72(0.12)$ & 2 \\
Andrenidae sp. & $1.56(0.08)$ & $1.91(0.10)$ & $6.02(0.04)$ & 3 \\
\hline
\end{tabular}

\section{Nectar Production}

All three Geodorum species had nectar in their flower spurs, but the amounts were too small to quantify. Sucrose concentrations of G. eulophioides, G. recurvum and $G$. densilforum flowers were $28,14-28$ and $56 \mathrm{mmol} / \mathrm{L}$, respectively.

\section{Observations of floral visitors}

\section{Geodorum eulophioides}

I carried out floral visitor observations on G. eulophioides for 61.20 h over 13 days ( 8 days in 2009, and 5 days in 2010). Floral visits were rare, and very brief (Fig. 6A). Most of the floral visits happened between 10:00h and 14:00h on sunny days. Two types of bees, Ceratina cognata Smith. and an undetermined Andrenidae sp., were the most common floral visitors. Together they were responsible for $96.9 \%$ of the observation time of all floral visitors (Fig. 6D).

The bee Ceratina cognata Smith. was the only floral visitor observed to remove and deposit pollinia for G. eulophioides, and was of an appropriate body size in height and width to enter flowers of all three orchid species. Although the body size of C. cognata 
was smaller than the pollination entrances of these orchid species, their active movements and searching behavior made pollinia removal and deposit likely. The undetermined Andrenidae bees was smaller than C. cognata, and did not match as well the floral morphology for pollination. Although it visited the flowers more frequently and stayed longer on flowers than did C. cognata, it was not seen to remove or deposit pollinia for any of the three orchid species.

Other rare visitors included butterflies, flies and two other types of bees. These visitors were observed to visit the flowers a few times during the entire observation period, but did not show any possible pollination behaviors. They usually flew around the flowers, settling on the petals or flying shallowly into the pollination passage for no more than 3 seconds.

The pollination efficiency of C. cognata for both G. eulophioides and G. recurvum was extremely low. During June and July in 2009 and 2010, I observed only two pollinia being removed, and only one deposited by C. cognata in G. eulophioides (in 2009).

\section{Geodorum recurvum}

I carried out floral visitor observation on $G$. recurvum for 48.9 h in 12 days ( 7 days in 2009, and 5 days in 2010 days). Floral visitors and their visitation patterns were very similar to those of G. eulophioides (Fig.6B\&6E), with C. cognata Smith. and Andrenidae sp. being the most common floral visitors. Together they were responsible for $89.5 \%$ of the total observed visitation time for all floral visitors (Fig. 6E). Ceratina cognata was the only floral visitor observed to remove and deposit pollinia for $G$. 
recurvum, as was the case for G. eulophioides. Only one pollinia removal and one deposit by C. cognata have been observed in G. recurvum (in 2010).

\section{Geodorum densiflorum}

I carried out floral visitor observations on $G$. densiflorum for 65.25 h over 11 days (1 day in 2009, and 10 days in 2010 days). Goedorum densiflorum was seen to be visited by only Andrenidae sp. and C. cognata (Fig. $6 C \& 6 F)$. However, no pollinia removal or deposition was observed during the entire observation period for this species.

Nevertheless, C. cognata was of the appropriate size for pollination and is a potential pollinator of this orchid species. 
Fig. 6 Pie charts of percentage of time (seconds) occupied by different floral visitors for the three sympatric orchid species, G. eulophioides (A \& D), G. recurvum (B \& E), andG. densiflorum (C \& F) in the Yachang Orchid Nature Reserve in southwestern China. Two types of pie charts were presented, one with the whole observation period (A, B, and C), and the other with only periods occupied by a visitor (D, E, and F).

A G. eulophioides ( $N=220,320$ seconds)

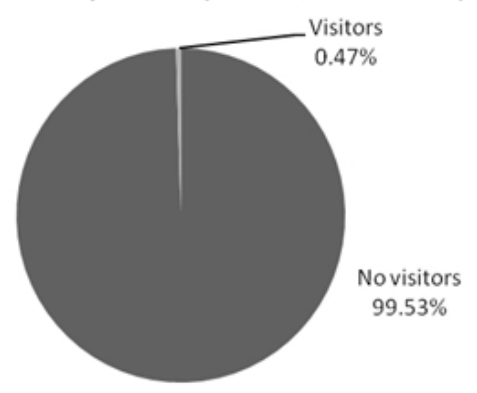

B G. recurvum $(\mathrm{N}=175,920 \mathrm{~s})$

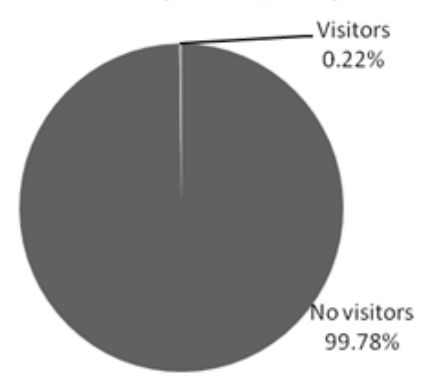

C G. densiflorum ( $\mathrm{N}=234,900 \mathrm{~s})$

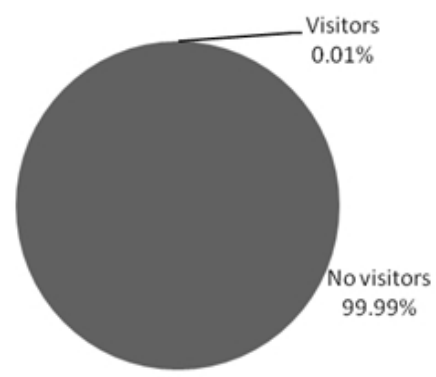

D G. eulophioides (with visitors: $N=1,034 s$ )
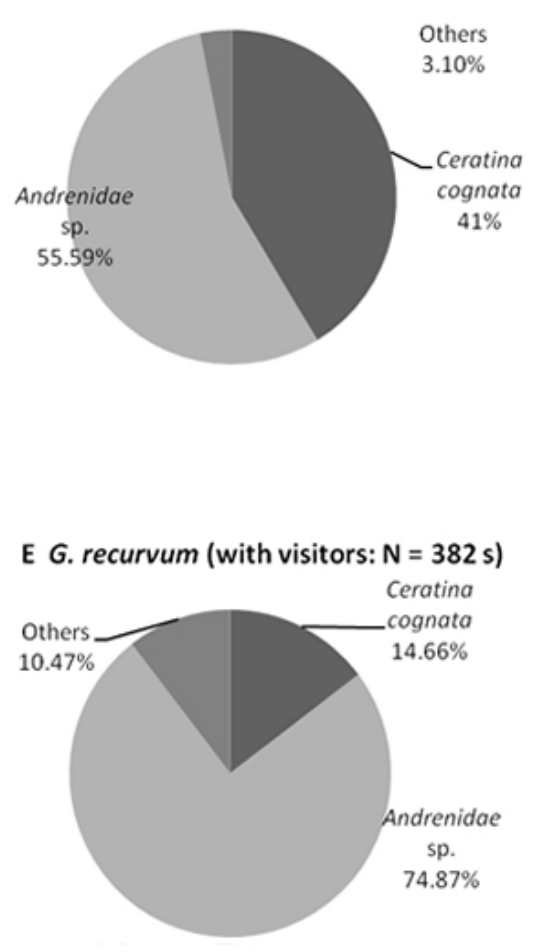

F G. densiflorum (with visitors: $N=28 \mathrm{~s}$ )

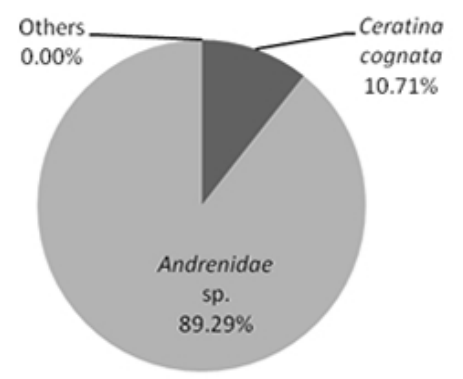


Comparison of floral visitation frequency across orchid species

One-way ANOVA indicated that the three Geodorum species differed significantly in the rate of visitation by C. cognata $\left(F_{2,367}=6.121, P=0.002 ;\right.$ Fig. $\left.7 A\right)$. Visitation rate by C. cognata to G. eulophioides and G. recurvum did not differ significantly $(P=0.057)$, though visitation on both those species was significantly higher than on G. densiflorum $(P=0.007)$. However, the visitation rate by $C$. cognata's to $G$. recurvum was not significantly different from that of visits to G. densiflorum $(P=0.624)$.

Visitation rates of all visitors pooled were significantly different $\left(F_{2,367}=11.564, P<\right.$ $0.001 ;$ Fig. $7 B$ ) among the three Geodorum species, with visitation rate to $G$. eulophioides significantly higher than that of G. recurvum and G. densiflorum; visitation rates were not different between G. recurvum and G. densiflorum. 
Fig. 7 Comparison of visitation rates by Ceratina cognata Smith. (A) and by all visitors pooled (B) among three Geodorum species.

A.

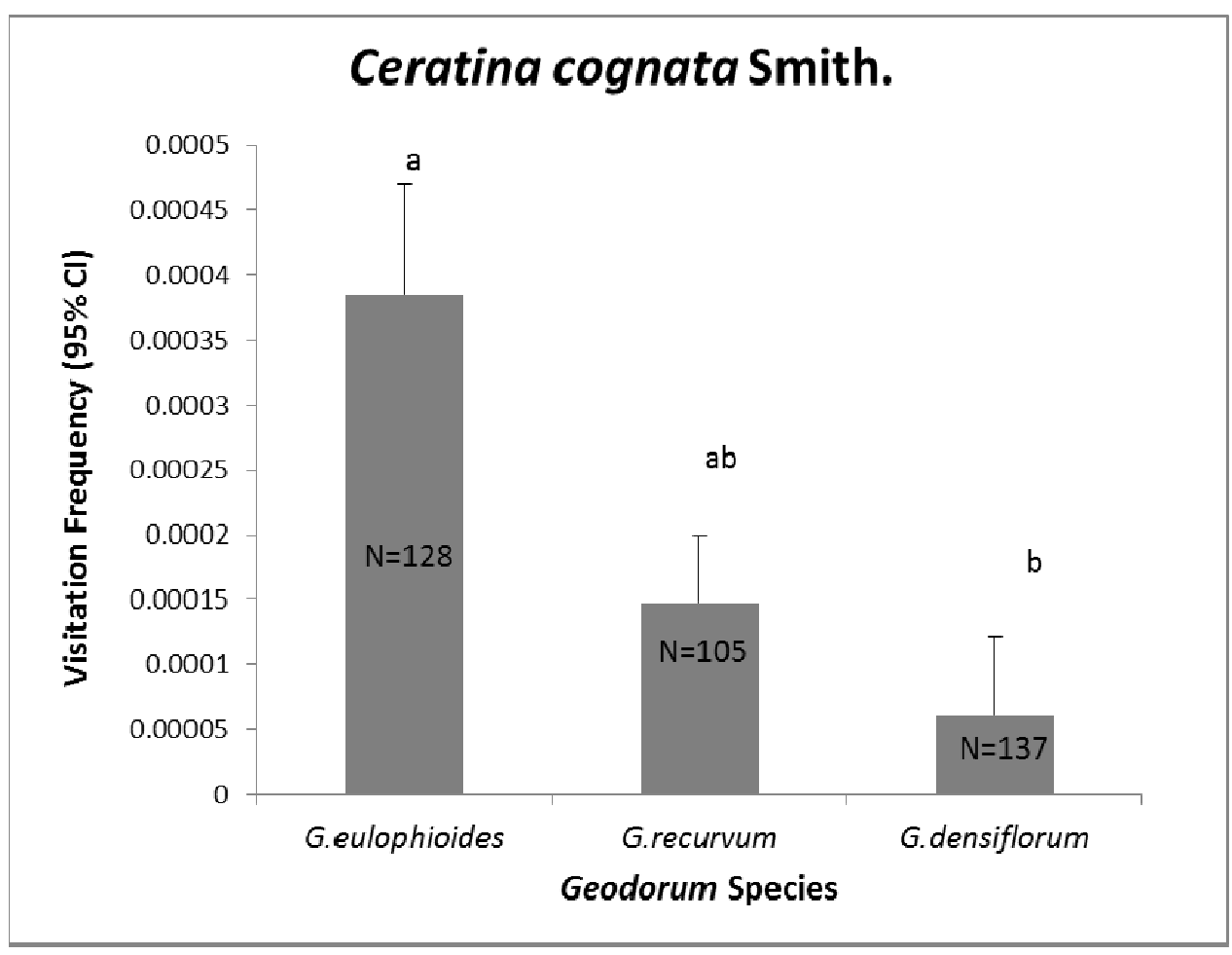


B.

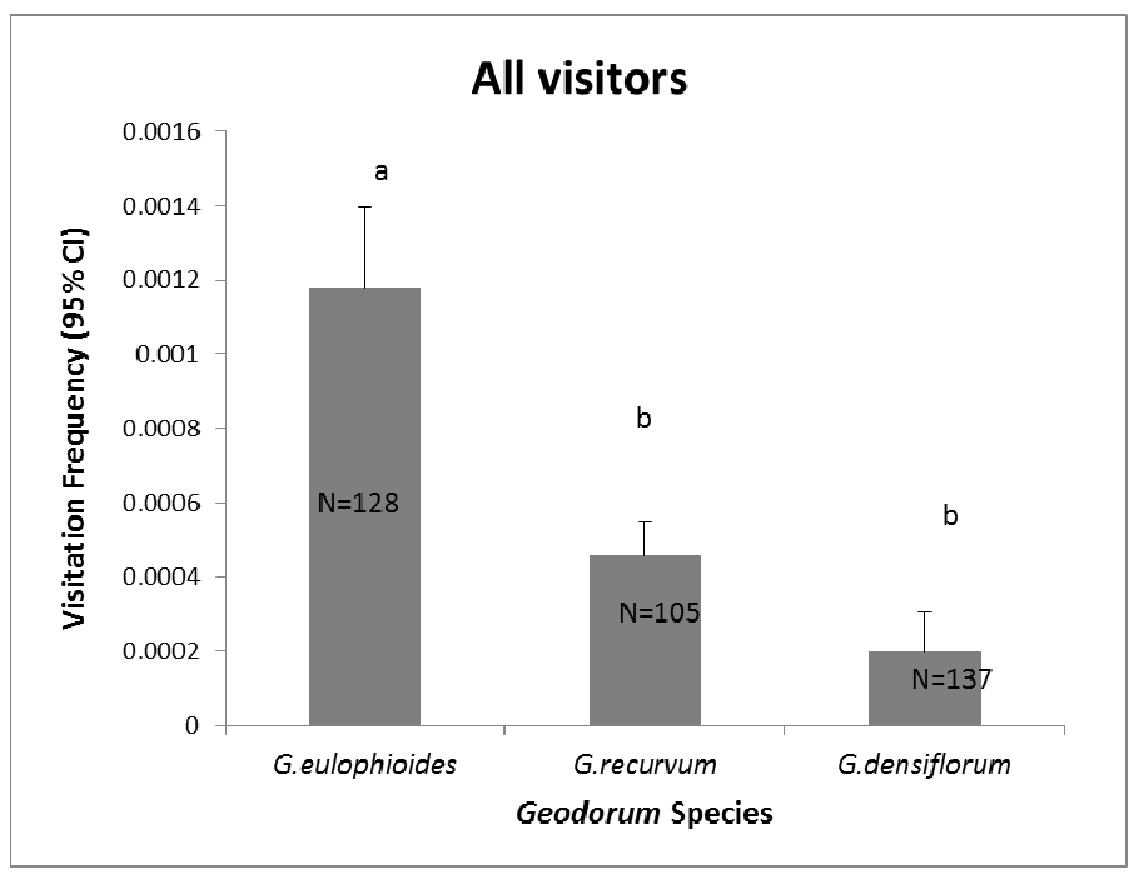

\section{Hybridization experiments}

The flowers of G. eulophioides are able to set fruits with hand-pollination with pollinia from $G$. recurvum. The fruits set rate from hybrid flowers of G. eulophioides (with $G$. recurvum) $(0.967 \pm 0.105$, mean \pm S.D., median $=1.00, \mathrm{~N}=10)$ was not significantly different from intraspecific cross-pollination treatment $(0.913 \pm 0.212$, median $=1.00, \mathrm{~N}=12$; Mann-Whitney $U$ test, $\mathrm{P}=0.771 ;$ Fig. $4 A$ ). Because of the unavailability of suitable G. eulophioides flowers at the end of its flowering period, I was only able to hand pollinate one replicate (4 flowers) of G. eulophioides treated with pollinia from $G$. densiflorum. The ovary of one of the four flowers swelled briefly after the hand-pollination, but then fell off in a week. The other three flowers did not show any enlargement of the ovaries (Fig. 4A). 
Flowers of Geodorum recurvum that received pollinia from G. eulophioides also set fruits. Similar to G. eulophioides, the fruit set percentage of hybrid treatment of $G$. recurvum $(0.880 \pm 0.173$, median $=1.00, \mathrm{~N}=4)$ was not significantly different from flowers of intra-specific cross-pollination treatments $(1.00 \pm 0.00$, median $=1.00, \mathrm{~N}=7$; Mann-Whitney $U$ test, $\mathrm{P}=0.315 ;$ Fig. $4 B$ ).

Flowers of G. densiflorum that received pollinia of G. eulophioides did not set any fruit. The percentage of fruit set, $0 \%(\mathrm{~N}=2)$, was significantly lower than that of intra-specific cross-pollination, $100 \%(\mathrm{~N}=3$; Mann-Whitney $U$ test, $\mathrm{P}=0.046 ;$ Fig. 4 C $)$.

The hybridized seeds of G. eulophioides had only marginally significant lower percentage of seeds with embryos than did outcross seeds (Mann-Whitney $U$ test, $\mathrm{P}=$ 0.057). I was not able to perform statistical tests on the other species because of lack of fruits. 


\section{CHAPTER VI DISCUSSION}

\section{Does the breeding system of G. eulophioides differ from those of its more common congeners?}

The answer to this question is complex. I found that G. eulophioides is self-compatible and the selfed flowers set as many fruits as the outcrossed flowers, suggesting the absence of inbreeding depression in this species. These breeding system traits were shared by both of the more common orchid congeners. However, $G$. eulophioides, as well as G. recurvum, was not capable of setting fruit without an insect vector, while $G$. densiflorum, the most widespread among the three congeners, was able to autonomously self-pollinate. Geodorum recurvum, despite its relatively wide geographic distribution, was equally rare on the local scale compared with $G$. eulophioides. Differences in the degree of pollinator dependency may partially explain the difference in local abundance among the three species. The added reproductive assurance of selfing may partially explain why G. densiflorum is much more widespread than G. eulophioides and G. recurvum.

Selfing occurs commonly among angiosperms, and is used by $\sim 20 \%$ of species as their primary mating strategy (Barrett, 2002). Selfing has been considered a reproductive assurance strategy to offset negative outcomes associated with the lack of pollinators (Darwin, 1877; Hagerup, 1952; Jain, 1976; Lloyd, 1979; Lloyd and Schoen, 1992; Lloyd, 1992; Kalisz and Vogler, 2003; Kalisz et al., 2004; Goodwillie et al., 2005) or conspecific mates (Lloyd and Schoen, 1992). The autonomous selfing capacity in G. densiflorum is likely adaptive because the species flowers from late June to late July, three to four weeks 
behind flowering of G. eulophioides and G. recurvum, when the region experiences the most frequent rains. More than $50 \%$ of the annual rainfall occurs from June to August (Huang et al. 2008). Rains can interfere with insect (including potential pollinator) activity. The different degree of pollinator availability among the three Geodorum species, especially caused by weather, might have led to the evolution of different breeding systems among the three sympatric congeners (Lloyd and Schoen, 1992; Kalisz and Vogler, 2003; Kalisz et al., 2004; Goodwillie et al., 2005).

\section{Does G. eulophioides have fewer pollinators and/or less frequent pollinator visits? Does G. eulophioides set fewer fruits per flower naturally?}

All three species produced nectar. Interestingly, Geodorum eulophioides, despite having nectar with lower sucrose concentration than G. densiflorum, received relatively more insect visits. Geodorum densiflorum received fewer insect visits, most likely because of its flowering during the most rainy period. In contrast, G. recurvum received fewer visits than G. eulophioides, maybe because of slightly lower nectar concentration, and/ or differences in flower coloration. Perhaps the red petal tip of G. eulophioides is more attractive to insects than the white petals in G. recurvum. Floral color constitutes an important cue for floral visitors in many other taxa (Weiss, 1995; Chittka et al., 2001). Both G. eulophioides and G. recurvum had much lower natural fruit set than $\operatorname{did} G$. densiflorum, likely a result of limited pollinator services observed for the former two species. Geodorum densiflorum also experienced extremely low pollinator services, but it can compensate for the limitation by autonomous selfing and likely did so during the study period. 
Nevertheless, visitation frequency and natural fruit set rate of all three Geodorum species were extremely low, in comparison with other orchids (Tremblay et al., 2005; Smithson, 2006; Cheng et al., 2009; Sun et al., 2011). In addition, the pollination efficiency was one order of magnitude lower than other studied orchid species (Gill, 1989; Neiland and Wilcock, 1998; Tremblay et al., 2005). Tremblay et al. (2005) reported natural fruit set to be $37.1 \pm 1.7$ for rewarding non-autogamous orchids, and $77.0 \pm 5.0 \%$ for autogamous orchids; in the Geodorum species fruit set was $0-0.0067 \%$.

\section{Do fruits of G. eulophioides have a smaller percentage of viable seeds than fruits of the} more common congeners?

Geodorum eulophioides fruits had a slightly higher percentage of seeds with embryos than did those of $G$. densiflorum. The percentages of naturally set seeds with embryos of both species were slightly lower than the average of other orchid species, but nonetheless within the range reported by Gale et al. (2010). It did not appear that the percentage of viable seeds is substantially lower in these Geodorum species.

\section{Inbreeding depression or lack thereof?}

For all three species, artificial self-pollination treatments resulted in similar fruit set to outcross treatments, indicating the lack of inbreeding depression, at least in the early stage of the orchids' life cycle. Inbreeding depression was also absent in the percentage of seeds with embryos in G. eulophioides, the only species with sufficient data to examine this possibility. Self-pollination in orchids is often associated with a higher level of fruit set (Ackerman, 1985; Catling, 1990; Tremblay et al., 2005), suggesting reproductive 
assurance (Hagerup, 1952; Jain,1976; Lloyd, 1979). Rare species with very small populations can experience severe inbreeding depression because they are more likely to inbreed (Barrett and Kohn, 1991), and suffer subsequent expression of deleterious recessive alleles (Charlesworth \& Charlesworth, 1979, 1987; Dudash, 1990; Barrett and Kohn, 1991; Tremblay et al., 2005). However, populations with a long history of inbreeding are also expected to show reduced or little inbreeding depression because chronic inbreeding may purge the deleterious, recessive alleles and lessen genetic load (Lande and Schemske, 1985; Charlesworth and Charlesworth, 1987, 1990; Barrett and Kohn, 1991; Tremblay et al., 2005), which may be the case with the locally rare $G$. eulophioides and G. recurvum, as well as the more abundant $G$. densiflorum because of its autonomous selfing. However, comparison between self and outcross seed performances in later stages of life cycle are needed to make firm conclusions about inbreeding depression.

\section{Can G. eulophioides hybrid with G. recurvum and G. densiflorum naturally?}

As Cozzolino and Widmer (2005) pointed out, the evolution of sister species is not always accompanied by parallel evolutionary shifts in pollination syndromes; closely related species, when growing sympatrically, sharing flowering periods and pollinator(s), are prone to high opportunities for interspecific hybridization (Van der Cingel 1995; Jersakova et al. 2006; Pellegrino et al., 2009). This may be the case with the sympatric $G$. europhioides and G. recurvum, as they showed similar morphological traits in pollination entrance, had near-complete overlap in flowering phenology, and shared pollinators. The results of hand pollination experiment also support this idea because hybrid flowers of $G$. 
eulophioides and G. recurvum set as many fruits as the intra-specific outcrossed treatment, and hybrid seeds showed the same level of viability, as indicated by presence of embryos, as the outcrossed seeds.

Though sympatric and having similar traits in pollination entrance, the chance of natural hybridization between G. eulophioides and G. densiflorum is very low, due to the brief- or non-overlapping flowering periods. In addition, hand-pollinated hybrid flowers between the two species failed to fruit. It appeared that there are effective pre-zygotic barriers between these two species. Though no artificial cross was performed between $G$. recurvum and G. densiflorum, it is also unlikely for these two species to naturally hybridize, according to the minimum overlap in flowering periods.

The lack of pre-mating barriers between G. eulophioide and G. recurvum, however, do not necessarily mean that the two species can form viable hybrids. Species integrity can be maintained by post-zygotic mechanisms (Stebbins, 1958; Coyne and Orr, 1998; Rieseberg and Carney, 1998; Tiffin et al., 2001), as seen in some Mediterranean food-deceptive orchids (Cozzolino et al., 2004, 2006; Scopece et al. 2007; Pellegrino et al, 2009), as well as Brazilian deceptive orchids (Silva-Pereira et al., 2007). Late post-zygotic mechanism, e.g., low germination rate and low growth rate or zero growth, may prevent G. eulophioides and G. recurvum from generating viable hybrids. To address this possibility, more data on the fate of hybrid seeds are needed. In addition, population genetic studies on both species at the same site are needed to understand the extent of introgression between the two species. 


\section{What are the potential consequences of natural hybridization?}

Rare and endangered species may lose their distinct gene pools when they hybridize with numerically superior congeners. Introgression (gene flow between cross-compatible interspecific populations) is achieved when hybrids backcross to one or both parental populations. Mating among hybrid individuals, and between hybrids and their parental individuals by backcrossing for many generations, can generate a hybrid swarm in which introgression has occurred to various degrees (Rhymer and Simberloff, 1996; Ferdy and Austerlitz, 2002). However, hybridization can also be a threat to small populations of rare species, even the gene pools are not mixed (Rhymer and Simberloff, 1996; Ellstrand, 1996; Martinsen, 2001).

Hybridization can promote the extinction of rare plants by reducing the reproductive success for parental plants and inhibiting population growth rate (Goodman 1987; Lande and Orzack 1988; Levin et al., 1996). It is a threat to the conservation of a rare and endangered species, if such cross-species mixing is the result of human activities or human-induced habitat alterations (Levin et al., 1996). For example, hybridization could reduce the growth rate of parental populations if hybrids competed for establishment microsites and resources with them (Eriksson and Ehrlen, 1992), especially when hybrids are more competitive than conspecifics (Hopper, 1978; Norrington-Davies, 1972). Hybridization may also increase herbivore and pathogen pressures because hybrids are often more sensitive to pest exploitation and they may serve as "staging areas" for pest colonization of parental species (Ericsson et al. 1993; Fritz et al. 1994; Whitham et al. 1994). 
The above scenarios may not apply to hybridization between G. eulophioides and G. recurvum, because hybridization between these two species, if indeed it occurs, is likely natural, and may have been taking place since the time of species formations. The genus level phylogeny built using molecular markers is desirable to better define the species boundaries in this case. Our study area in southwestern China is at or near the northern boundary for G. recurvum. It may be possible that G. eulophioides diverged from G. recurvum, driven by the unique ecological conditions along the lower valleys of the Hongshui River. These ecological conditions are believed to have shaped a subspecies of tropical pine, Pinus yunnanensis var. tennifolia, that is endemic to several valleys of the Nanpanjiang and Hongshui rivers (Li and Wang, 1981), including areas where $G$. eulophioides were also found.

There is an urgent need to understand species relationships between G. eulophioides and G. recurvum and the role of natural hybridization in maintaining the species, or perhaps, subspecies definitions. Understanding how levels and types of habitat alterations may alter the potential interspecies mating may help to shape management recommendations.

\section{Conservation implications for the rare G. eulophioides}

While we cannot change the breeding system traits of the rare Geodorum species, I can recommend management measures that will improve pollinator services that $G$. eulophioides (and G. recurvum) depend on for greater fruit set. The site that hosts the largest known population of G. eulophioides in southwest China was illegally cleared for Eucalyptus sp. and corn plantings by local villagers in 2008 and 2009. Although farming 
was stopped in 2009 , the habitat is still in a deteriorated state that needs active restoration. Population densities of both Ceratina cognata Smith. and Andrenidae bees at that site may have declined during the last 3 years. The visitation rate of $C$. cognata to $G$. eulophioides went from $5.37 \times 10^{-4}$ visit per flower per minute in 2009 to $4.9 \times 10^{-5}$ in 2010, nearly a 10-fold decline. Casual observations at the same site suggest that there may have been even fewer floral visits by the bees in 2011 .

Geodorum's primary pollinator, C. cognata, and frequent visitor Andrenidae bees, were observed to visit native Asteraceae species very frequently during the Geodorum flowering seasons in 2009 and 2010. Density of these native plants, likely the main food source to sustain the bee population, were greatly reduced by farming activities and the subsequent strong invasion of the habitat by Chromolaena odoratum, a widespread introduced species in southern China, which flowers during the fall, after the flowering periods of the orchids. While I need more studies to quantify the impacts of habitat destruction and of the introduced invasive Chromolaena odoratum populations on pollinator abundance and activities, with the information at hand, I conclude that a community-based conservation and management approach is required to protect and restore G. eulophioides and its sympatric congeners in the Yachang Reserve. There is a pressing need to restore diverse native nectar plants that are blooming at the same time as the Geodorum species. Such floral resources will assure that visitors are present, and pollinators are available, during the flowering periods of the rare orchids.

This recommendation is supported by observations from another 0.5 acre site where a small population of $G$. eulophioides and G. recurvum grow in a relatively undisturbed situation. This site was discovered in the summer of 2011, about $20 \mathrm{~km}$ away from our 
original study site, and on the other side of Hongshui River. The overstory consisted of mostly the Yunnan thin-leaved pine, while the understory was composed of mostly native shrubby plants and grasses. The exotic Chromolaena odoratum was present but rare. Individuals of G. eulophioides and G. recurvum here were robust. More importantly, there was also much more active insect activity, including C. cognata bee and Andrenidae bees, known pollinator and visitors of the orchids.

Suitable habitats for Geodorum eulophioides are low elevation areas along the Hongshui River and its tributaries, places where farmers also find it convenient to farm. Careful mediation of the conflicts between local communities and the Yachang Reserve will be needed to establish in-situ conservation programs for the species. Ex-situ conservation, i.e., long-term seed storage and living collection in off-site botanical gardens, as well as in-situ population augmentation, reintroduction and even managed relocation should all be pursued in light of the tense park-people relations. Finally, I do not recommend harvesting naturally set fruits for the conservation measures proposed above. Instead, I recommend the use of seeds that resulted from hand pollination. Due to the uncertainty of inbreeding depression, I suggested that outcrossed seeds should be used for ex-situ collection and restoration.

\section{Conclusions}

The rare and geographically limited G. eulophioides has very few differences in breeding and pollination traits from that of G. recurvum. The latter is equally rare on both the local and regional scale, despite having a wider geographic distribution. Both have traits differing from $G$. densiflorum, the most common of the three congeners. These 
differences help to explain the difference in abundance among these species. In particular, findings in pollination and fruit set patterns guide us to formulate data-driven conservation measures. 


\section{REFERENCES}

Ackerman, J.D. 1985. Pollination of tropical and temperate orchids. In: Tan KW [ed.] Proceedings of the eleventh world orchid conference. Miami, 98-101.Allendorf, F.W., R. F. Leary, P. Spruell, and J. K. Wenburg. 2001. The problems with hybrids: setting conservation guidelines. Trends in Ecology \& Evolution 16: 613-622.

Anderson, E. 1948. Hybridization of the habitat. Evolution 2:1-9.

Anderson, E., 1949. Introgressive Hybridization. Wiley, New York.

Arnold, M. L., and B. D. Bennett. 1993. Natural hybridization in Louisiana Irises: genetic variation and ecological determinants. In R. G. Harrison [Ed.]. Hybrid zones and the evolutionary process. Oxford University Press, New York. 115-139.

Arnold, M.L., 1997. Natural Hybridization and Evolution. Oxford University Press, New York.

Barrett, S. C. H., and J. R. Kohn. 1991. Genetic and evolutionary consequences of small population size in plants: implications for conservation. In D. A. Falk and K. E. Holsinger [eds.] 3-30. Genetics and conservation of rare plants. New York. Oxford. Oxford University Press, New York, USA.

Barrett, S. C. H. 2002. Evolution of sex: The of plant sexual diversity. Nature reviews. Genetics 3: 274-284.

Baskin, J., K. M. Snyder, J. L. Walck, and C. C. Baskin. 1997. The comparative autecology of endemic, globally-rare, and geographically-widespread, common plant species: Three case studies. The Southwestern naturalist 42: 384-399.

Barton, N.H., 2001. The role of hybridization in evolution. Molecular Ecology 10: $551-568$.

Bernhardt, P. P., and R. Edens-Meier. 2010. What We Think We Know vs. What We Need to Know About Orchid Pollination and Conservation: Cypripedium L. as a Model Lineage. The Botanical review 76: 204-219.

Bevill, R. L., and S. M. Louda. 1999. Comparisons of Related Rare and Common Species in the Study of Plant Rarity. Conservation Biology 13: 493-498.

Burne, H. M., C. J. Yates, and P. G. Ladd. 2003. Comparative population structure and reproductive biology of the critically endangered shrub Grevillea althoferorum and two closely related more common congeners. Biological Conservation 114: 53-65. 
Catling, P.M. 1990. Auto-pollination in the Orchidaceae. In: Arditti J, [ed.] Orchid biology: reviews and perspectives, V. 121-158. Timber Press, Portland, USA.

Charlesworth, D., and B. Charlesworth. 1979. The evolutionary genetics of sexual systems in flowering plants. Proceedings of the Royal Society of London B 205: $511-530$.

Charlesworth, D., and B. Charlesworth. 1987. Inbreeding depression and its evolutionary consequences. Annual Review of Ecology and Systematics 18: 237-268.

Cheng, J., J. Shi, F. Shangguan, A. Dafni, Z. Deng, and Y. Luo. 2009. The pollination of a self-incompatible, food-mimic orchid, Coelogyne fimbriata (Orchidaceae), by female Vespula wasps. Annual of Botany 104: 565-571.

Chen, X., Z. Liu, G. Zhu, K. Liang, J. Ji, Y. Luo, P. Cribb, et al. 2009. Orchidaceae. in Z. Y. Wu, P. Raven, \& D. Y. Hong [eds.]. Flora of China, vol 25. Science Press, Beijing, China \& Missouri Botanical Garden Press, St. Louis, USA.

Chittka, L. J., A. Sapethe, A. Schmidt, and A. Hickelsberger. 2001. Adaptation, constraint, and chance in the evolution of flower color and pollinator color vision. In Chittka L, \& thomson J. D. [eds.]. Cognitive Ecology of Pollination. Cambridge University Press, Cambridge, UK.

Corlett, R. T., and J. V. Lafrankie. 1998. Potential impacts of climate change on tropical Asian forests through an influence on phenology. Climatic Change 39: 439-453.

Corlett, R. T. 2009. Seed Dispersal Distances and Plant Migration Potential in Tropical East Asia Seed Dispersal in Tropical East Asia. Biotropica 41: 592-598.Coyne, J.A., and H. A. Orr. 1998. The evolutionary genetics of speciation. Philosophical Transactions of the Royal Society B: Biological Sciences 353: 287-305.

Cozzolino S, S. D'Emerico, and A. Widmer. 2004. Evidence for reproductive isolate selection in Mediterranean orchids: karyotype differences compensate for the lack of pollinator specificity. Proceedings of the Royal Society B: Biological Sciences 271: S259-S262.

Cozzolino S., Widmer A. 2005. The evolutionary basis of reproductive isolation in Mediterranean orchids. Taxon 54: 977-985.

Cozzolino S., Nardella A.M., Impagliazzo S., Widmer A., Lexer C. 2006. Hybridization and conservation of Mediterranean orchids: should we protect the orchid hybrids or the orchid hybrid zones? Biological Conservation 129: 14-23.

Crawford, D. J., R. Witkus, and T. F. Stuessy. 1987. Plant evolution and speciation on oceanic islands. Pages 183-199 in K. M. Urbanska, editor. Differentiation patterns in higher plants. Academic Press, London. 
Dafni, A. 1992. Pollination Ecology: a practical approach. Institute of Evolution Haifa University. Oxford University Press, New York, USA.

Darwin, C. 1862. The various contrivances by which British and foreign orchids are fertilized by insects. John Murray, London, UK.

Darwin, C. 1877. The various contrivances by which orchids are fertilized by insects. 2nd edition. John Murray, London, UK.

Dixon, K. W., S. P. Kell, R. L. Barrett, and P. J. Cribb. 2003. Orchid conservation. Kota Kinabalu, Sabah: Natural History Publications. Borneo.

Dixon, K. W. 2009. Pollination and Restoration. Science 325: 571-573.

Dressler, R.L. 1981. The orchids: natural history and classification. Harvard University Press, Cambridge, USA.

Dressler, R.L. 1993. Phylogeny and classification of the orchid family. Dioscorides, Portland, Oregon, USA.Dudash, M. R. 1990. Relative fitness of selfed and outcross progeny in a self-compatible, protandrous species, Sabatia angularis L. (Gentianaceae), a comparison in three environments. Evolution 44: 1129-1139.Ellstrand N.C., Whitkus R., Rieseberg L.H. 1996. Distribution of spontaneous plant hybrids. Proceedings of the Academy of Natural Sciences USA 93: 5090-5093.

Ellstrand, N.C., Schierenbeck, K.A., 2000. Hybridization as a stimulus for the evolution of invasiveness in plants. Proceedings of the Academy of Natural Sciences USA 97: 7043-7050.

Ericson, L., J. J. Burdon, and A. Wennstrom., 1993. Inter-specific host hybrids and phalacrid beetles implicated in the local survival of smut pathogens. Oikos 68: 393-400.

Eriksson, O., and J. Ehrlen. 1992. Seed and microsite limitation of recruitment in plant populations. Oecologia 91:360-364.

Feng C, Z. Deng, D. Cai, T. Wu, H. Jia, L. Bai, Z. Zhao, and Y. Su. 2012. Status quo and conservation strategies of wild orchid resources in Guangxi Yachang Forests. Plant Science Journal. In press (in Chinese with an English abstract).Ferdy, J.B., Austerlitz, F., 2002. Extinction and introgression in a community of partially cross-fertile plant species. American Naturalist 160: 74-86.

Fiedler, P. L., and J. J. Ahouse. 1992. Hierarchies of cause: toward an understanding of rarity in vascular plant species. In: Fiedler, P.L., Jain, S.K. [Eds.], Conservation Biology. Chapman and Hall, New York, USA. 
Field, A. 2005. Discovering statistics using SPSS. SAGE Publications. London, UK.Fritz, R. S., C. M. Nichols-Orians, and S. J. Brunsfeld. 1994. Interspecific hybridization of plants and resistance to herbivores: hypotheses, genetics and variable responses in a diverse herbivore community. Oecologia 97:106-117.

Gale, S. W., j. Yamazaki, M. J. Hutchings, T. Yukawa, and K. Miyoshi. 2010. Constraints on establishment in an endangered terrestrial orchid: a comparative study of in vitro and in situ seed germinability and seedling development in Nervilia nipponicab. Botanical Journal of the Linnean Society 163: 166-180.

Gaston, K. J., and W. E. Kunin. 1997. Rare-common differences: an overview. In: Kunin, W.E., Gaston, K.J. [Eds.], The Biology of Rarity. Chapman and Hall, London, UK.

Gill, D. E. 1989. Fruiting failure, pollinator inefficiency, and speciation in orchids. In: Otte D, Endler JA. [eds.] Speciation and its consequences. 458-481. Sinauer Associates, Sunderland, Massachusetts, USA.Gillett, G. W. 1972. The role of hybridization in the evolution of the Hawaiian flora. Pages 205-219 in D. H. Valentine, editor. Taxonomy, phytogeography, and evolution. Academic Press, London.

Goodman, D. 1987. The demography of chance extinction. In M. E. Soule [Ed]. $11-34$. Viable populations for conservation. Cambridge University Press, Cambridge, England.

Grant, V. 1981. Plant Speciation. Columbia University Press, New York.

Groom, M. 1998. Allee Effects Limit Population Viability of an Annual Plant. The American Naturalist 151: 487-496.Hagerup, O. 1952. Bud autogamy in some northern orchids. Phytomorphology 2: 51-60.

Hopper, S. D. 1978. An experimental study of competitive interference between Anzgiozanthos manglesii D. Don, A. humilis Lindl. and their F, hybrids (Haemodoraceae). Australian Journal of Botany 26:807-817.

Huang, C, J. Chen, C. Feng, Z. Lu, and J. Li. 2008. Characteristics of Climate Vertical Distribution in Yachang Orchid Nature Reserve. Journal of Northwest Forestry University 23(5): 39-43 (in Chinese with English abstract).

Jain, S. K. 1976. The evolution of inbreeding in plants. Annual Review of Ecology and Systematics 7: 469-495.

Jersakova, J., S. D. Johnson, P. Kindlmann. 2006. Mechanisms and evolution of deceptive pollination in orchids. Biological Reviews 81: 219-235. 
Johnson, S. D., H. P. Linder, and K. E. Steiner. 1998. Phylogeny and radiation of pollination systems in Disa (Orchidaceae). American Journal of Botany 85: 492-411.

Kalisz, S., and D. W. Vogler. 2003. Benefits of autonomous selfing under unpredictable pollinator environments. Ecology (Durham) 84: 2928-2942.

Kalisz, S., D. W. Vogler, and K. M. Hanley. 2004. Context-dependent autonomous self-fertilization yields reproductive assurance and mixed mating. Nature (London) 430: 884-887.

Kunin, W. E., and K. J. Gaston. 1993. The biology of rarity: Patterns, causes and consequences. Trends in ecology \& evolution (Amsterdam) 8: 298-301.

Lande, R., and D. W. Schemske.1985. The Evolution of Self-Fertilization and Inbreeding Depression in Plants. I. Genetic Models. Evolution 39: 24-40.Lande, R., and S. H. Orzack. 1988. Extinction dynamics of age-structured populations in a fluctuating environment. Proceedings of the National Academy of Sciences, U.S.A. 85: 7418-742 1 .

Levin, D. A., J. F. Ortega, and R. K. Jansen. 1996. Hybridization and the Extinction of Rare Plant Species. Conservation Biology 10: 10-16.

Li, Z. J and X. P. Wang. 1981. Geographic distribution of Pinus yannanensis var. tennifolia and its relationship with environmental variables. Acta Phytoecologia et Geobotanica Sinica 5 (1): 28-37. (In Chinese with English abstract).

Liu, H. 2010. Geodorum eulophioides - challenges in conserving one of the rarest Chinese orchids. Orchids Magazine, March issue: 161-162.

Lloyd, D. 1979. Some reproductive factors affecting the selection of self-fertilization in plants. American Naturalist 113: 67-79.

Lloyd, D., and D. J. Schoen. 1992. Self-fertilization and cross-fertilization in plants: 1. Functional dimensions. International journal of plant sciences 153: 358-369.

Lloyd, D. 1992. Self-fertilization and cross-fertilization in plants: II. The selection of self-fertilization. International journal of plant sciences 153: 370-380.

Martinsen G. D., T. G. Whitham, R. J. Turek, and P. Keim. 2001. Hybrid populations selectively filter gene introgression between species. Evolution 55: 1325-1335.

Mayr, E., 1992. A local flora and the biological species concept. American Journal of Botany 72: 222-238. 
Menges, E. S., E. O. Guerrant, Jr, and S. Hamzé. 2004. Effects of seed collection on the extinction risk of perennial plants. In Ex Situ Plant Conservation: Supporting Species Survival in the Wild. In: E. O. J. Guerrant, K. Havens, and M. Maunder [eds.]. 305-324. Island Press, Covelo, USA.

Neiland, M.R. and C. C. Wilcock. 1998. Fruit set, nectar reward, and rarity in the Orchidaceae. American Journal of Botany 85: 1657-1671.

Norrington-Davies, J. 1972. Diallel analysis of competition between some barley species and their hybrids. Euphytica 21:292-308.

Pellegrino, G., F. Bellusci, and A. Musacchio. 2009. Genetic integrity of sympatric hybridising plant species: the case of Orchis italica and O. anthropophora. Plant Biology 11: 434-441.

Rabinowitz, D. 1981. Seven forms of rarity. In H. Synge [ed.] The biological aspects of rare plant conservation. Wiley, New York, USA.

Rhymer, J. M., and D. Simberloff. 1996. Extinction by hybridization and introgression. Annual Review of Ecology and Systematics 27:83-109.

Rieseberg, L. H. 1991. Hybridization in rare plants: insights from case studies in Cerocarpus and Helianthus. Pages 171-181 in D. A. Falk and K. E. Holsinger, editors. Genetics and conservation of rare plants. Oxford University Press, New York.

Rieseberg, L.H. 1997. Hybrid origins of plant species. Annual Review of Ecology, Evolution and Systematics 28: 359-389.

Rieseberg, L.H., and S. E. Carney. 1998. Plant hybridization. New Phytologist 140: 599-624.

Scopece, G., A. Musacchio, A. Widmer, and S. Cozzolino. 2007. Patterns of reproductive isolation in Mediterranean orchids. Evolution 61: 2623-2642.

Shrader-Frechette, K. S., and E. D., McCoy. 1993. Method in ecology. strategies for conservation. Cambridge: Cambridge Univ. Press

Smithson, A. 2002. The consequences of rewardlessness in orchids: reward supplementation experiments with Anacamptis morio (Orchidaceae). American Journal of Botany 89: 1579-1587.

Smithson, A. 2006. Pollinator limitation and inbreeding depression in orchid species with and without nectar rewards. New Phytologist 169: 419-430.

Stebbins, G.L. 1958. The inviability, weakness and sterility of interspecific hybrids. Advances in genetics 9: 147-215. 
Stebbins, G. L. 1959. The role of hybridization in evolution. Proceedings of the American Philosophical Society 103:231-251.

Sun, H., B. Huang, X. Yu, Y. Kou, D. An, Y. Luo, and S. Ge. 2011. Reproductive isolation and pollination success of rewarding Galearis diantha and non-rewarding Ponerorchis chusua (Orchidaceae). Annals of Botany 107: 39-47.

Swarts, N. D., and K. W. Dixon. 2009. Terrestrial orchid conservation in the age of extinction. Annals of botany 104: 543-556.

Tanaka, N., T. Yukawa, K. M. Htwe, T. Koyama, and J. Murata. 2011. New or noteworthy plant collections from Myanmar (7): fourteen additional species of Orchidaceae. Acta Phytotaxonomica et Geobotanica 61: 161-165.

Tiffin, P., M. S. Olson, and L. C. Moyle. 2001. Asymmetrical crossing barriers in angiosperms. Proceedings of the Royal Society B: Biological Sciences 268: 861-867.

Tremblay, R. 1992. Trends in pollination biology of the Orchidaceae: evolution and systematics. Canadian Journal of Botany 70: 642-650.

Tremblay, R. , J. D. Ackeman, J. K. Zimmerman, and R. N. Calvo. 2005. Variation in sexual reproduction in orchids and its evolutionary consequences: a spasmodic journey to diversification. Biological Journal of the Linnean Society 84: 1-54.Van der Cingel, N.A., 1995. An Atlas of Orchid Pollination - European Orchids. Balkema, Rotterdam.

Van Der Pijl, L., and C. H. Dodson. 1966. Orchid flowers: their pollination and evolution. University of Miami Press, Coral Gables, Florida, U.S.A.Weiss, M. R. 1995. Floral color change: a widespread functional convergence. American Journal of Botany 82: 167-185. Whitham, T. G., P. A. Morrow, and B. M. Potts. 1994. Plant hybrid zones as centers of biodiversity: The herbivore community of two endemic Tasmanian eucalypts. Oecologia 97:481-490.

Willing, B. and E. Willing. 1977. Bibliographie uber die Orchideen Europas und der Mittelmeerlander 1744-1976. Willdenowia 11: 1-325.

Willing, B. and E. Willing. 1985. Bibliographie uber die Orchideen Europas und der Mittelmeerlander. Englera 5: 1-280. 


\section{APPENDICES}

APPENDIX I Statistical results for rates of fruit set under different treatments of hand-pollination experiment for different Geodorum species.

\begin{tabular}{lllllll}
\hline Species & Treatment & Mean & N & S. D. & S. E. & Median \\
\hline G. eulophioides & Self & 0.7847 & 12 & 0.3835 & 0.1107 & 1.0000 \\
& Outcross & 0.9132 & 12 & 0.2121 & 0.0612 & 1.0000 \\
& Bagged & 0.0200 & 10 & 0.0633 & 0.0200 & 0.0000 \\
& Control & 0.0552 & 24 & 0.0722 & 0.0147 & 0.0000 \\
& Hybrid with G. $r$. & 0.9667 & 10 & 0.1054 & 0.0333 & 1.0000 \\
& Hybrid with G. .. & 0.2500 & 1 & & & 0.2500 \\
\hline G. recurvum & Self & 1.0000 & 4 & 0.0000 & 0.0000 & 1.0000 \\
& Outcross & 1.0000 & 4 & 0.0000 & 0.0000 & 1.0000 \\
& Bagged & 0.0000 & 5 & 0.0000 & 0.0000 & 0.0000 \\
& Control & 0.0107 & 16 & 0.0297 & 0.0074 & 0.0000 \\
& Hybrid with G. e. & 0.8804 & 7 & 0.1733 & 0.0655 & 1.0000 \\
\hline G. densiflorum & Self & 0.9500 & 5 & 0.1118 & 0.0500 & 1.0000 \\
& Outcross & 1.0000 & 3 & 0.0000 & 0.0000 & 1.0000 \\
& Bagged & 0.2076 & 11 & 0.3772 & 0.1137 & 0.0000 \\
& Control & 0.1393 & 26 & 0.1595 & 0.0313 & 0.1067 \\
& Hybrid with G. e. & 0.0000 & 2 & 0.0000 & 0.0000 & 0.0000 \\
\hline
\end{tabular}

APPENDIX II Statistical results for percentages of seeds with embryos under different treatments for G. eulophioides.

\begin{tabular}{lllllll}
\hline Treatment & Mean & N & S. D. & S. E. & Median & Range \\
\hline Self & 0.9470 & 3 & 0.0335 & 0.0194 & 0.9516 & $0.9114 \sim 0.9780$ \\
Outcross & 0.9677 & 5 & 0.0221 & 0.0099 & 0.9702 & $0.9315 \sim 0.9904$ \\
Hybrid & 0.9002 & 5 & 0.0738 & 0.0330 & 0.9465 & $0.7821 \sim 0.9530$ \\
Control & 0.6174 & 7 & 0.2898 & 0.1095 & 0.6587 & $0.0005 \sim 0.8900$ \\
\hline
\end{tabular}

